\title{
2012 Annual Report Research Reactor Infrastructure Program
}

November 2012

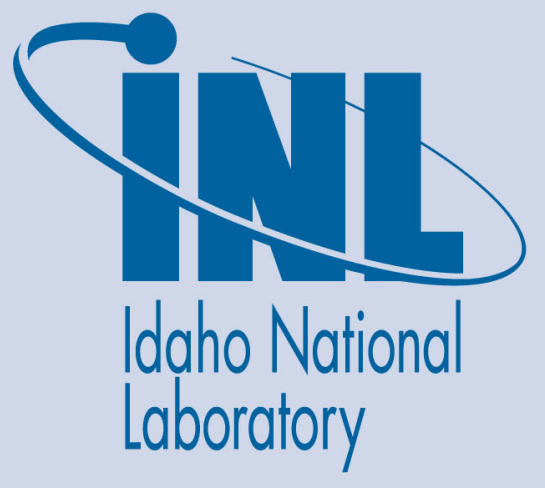

The INL is a U.S. Department of Energy National Laboratory operated by Battelle Energy Alliance 
INL/EXT-12-27816

\section{Annual Report Research Reactor Infrastructure Program}

November 2012

\section{Idaho National Laboratory \\ Idaho Falls, Idaho 83415}

http://www.inl.gov

Prepared for the

U.S. Department of Energy

Office of Nuclear Energy

Under DOE Idaho Operations Office

Contract DE-AC07-05ID14517 


\section{Annual Report for the Research Reactor Infrastructure Program}

Approved By

Douglas $K$ onovell Douglas K. Morrell

RRI Project Manager

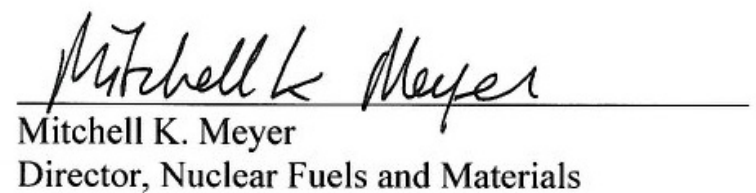

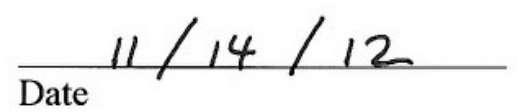

$\frac{11 / 26 / 12}{\text { Date }}$ 


\section{CONTENTS}

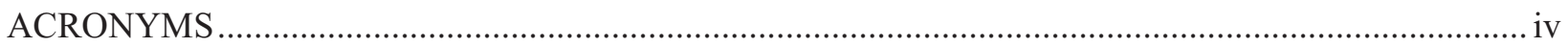

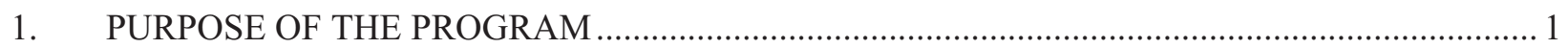

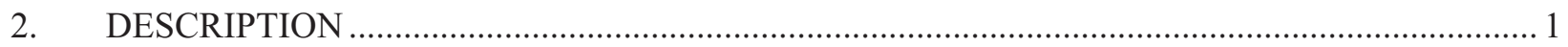

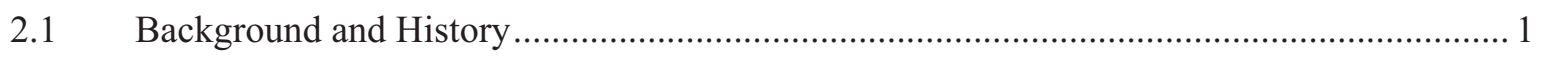

2.2 National Value of University Reactor Programs ........................................................ 2

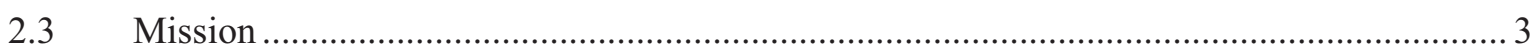

2.4 University Reactor Information.............................................................................. 3

3. PROJECT ACCOMPLISHMENTS DURING FISCAL YEAR 2012 _........................................ 7

3.1 Fuel Fabrication and Delivery to Universities........................................................... 7

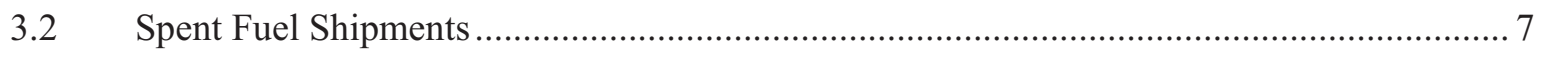

3.3 Project Management and Technical Support ........................................................... 8

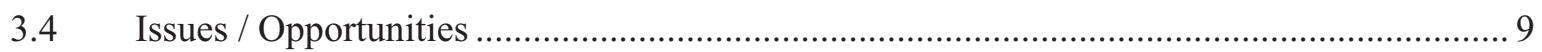

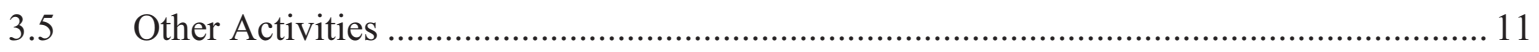

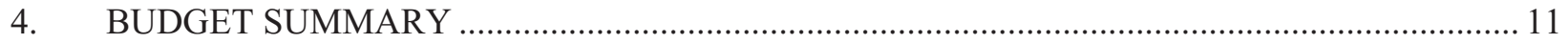

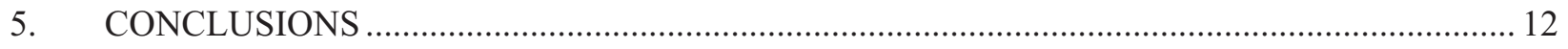

Appendix A Memorandum to File - M. Rowan .................................................................................. A1

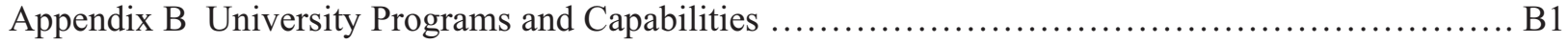




\section{ACRONYMS}

$\begin{array}{ll}\text { AEC } & \text { Atomic Energy Commission } \\ \text { B\&W } & \text { Babcock and Wilcox } \\ \text { BEA } & \text { Battelle Energy Alliance } \\ \text { DOE } & \text { Department of Energy } \\ \text { DOE-ID } & \text { Department of Energy Idaho Operations Office } \\ \text { ERDA } & \text { Energy Research and Development Administration } \\ \text { HEU } & \text { Highly Enriched Uranium } \\ \text { INL } & \text { Idaho National Laboratory } \\ \text { LEU } & \text { Low Enriched Uranium } \\ \text { MIT } & \text { Massachusetts Institute of Technology } \\ \text { MURR } & \text { University of Missouri Research Reactor } \\ \text { NRC } & \text { Nuclear Regulatory Commission } \\ \text { RRI } & \text { Research Reactor Infrastructure } \\ \text { RSD } & \text { Required Shippers Data } \\ \text { SNM } & \text { Special Nuclear Material } \\ \text { TI } & \text { TRIGA International } \\ \text { TRIGA } & \text { Training, Research, Isotope production, General Atomics } \\ \text { URFAP } & \\ \text { Thiversity Reactor Fuel Assistance Program }\end{array}$




\section{PURPOSE OF THE PROGRAM}

The Idaho National Laboratory (INL) manages and provides project management, technical support, quality engineering, quality inspection and nuclear material support for the Department of Energy (DOE) Research Reactor Infrastructure Program (RRI). This program provides fresh, unirradiated nuclear reactor fuel for United States domestic University Test, Research and Training Reactor Programs. The two fuel types fabricated for the program, plate fuel and Training, Research, Isotope Production, General Atomics (TRIGA) fuel are obtained through subcontracts with two fuel fabricators, Babcock and Wilcox Nuclear Operations Group (B\&W) and TRIGA International (TI). Respectively, these subcontractors fabricate high and low enriched uranium aluminide, silicide and TRIGA fuel on a recurring basis. The program is also responsible for funding the return of the DOE-owned, irradiated nuclear fuel over the life of the program.

\section{DESCRIPTION}

\subsection{Background and History}

The Atomic Energy Commission (AEC) initiated the Research Reactor Infrastructure program (formerly known as the University Reactor Fuel Assistance Program) by issuing grants to universities to assist in the procurement of reactor fuel. Because the federal government funds this program and owns the uranium, title of the fuel is retained by the government. Beginning in 1974, increased physical security requirements for safeguarding special nuclear material required fuel manufacturing licensees to upgrade their facilities at significant costs which caused many fuel manufacturers to discontinue operations.

Because possible foreign fuel suppliers were not allowed to possess U.S. government owned enriched uranium needed to fabricate the fuel in the mid 1970s only Texas Instruments and Atomics International were manufacturing plate-type fuel for the Energy Research and Development Administration (ERDA), (Texas Instruments was manufacturing oxide fuel and Atomics International was manufacturing aluminide fuel). Both Texas Instruments and Atomics International were only accepting cost plus fixed fee contracts, which were very difficult for universities to handle and manage. Seven plate-type reactors had to sharply reduce reactor operations and faced the inability to operate because of lack of fuel. In 1977, an organized university consortium requested ERDA assistance in providing platetype fuel through use of existing government subcontracts using government owned equipment at Atomics International, where ERDA had a contract to manufacture aluminide plate-fuel.

In 1977, the ERDA Idaho Operations Office was assigned responsibility for the fuel assistance program which was managed by EG\&G Idaho, the INEL prime subcontractor. In late 1977 ERDA became Department of Energy. Fuel deliveries under this program began in 1978.

In 1985, the aluminide plate-type fuel subcontract was transferred from Atomics International to the Babcock \& Wilcox Nuclear Operations Group at Lynchburg, Virginia. Currently all plate fuel for the RRI program is fabricated by Babcock and Wilcox.

In 1958 General Atomics in San Diego, California started manufacturing TRIGA fuel which was used to operate their newly designed TRIGA reactors.. In 1996 General Atomics entered a joint venture 


\section{ANNUAL REPORT FOR THE RESEARCH REACTOR INFRASTRUCTURE PROGRAM}

with CERCA to form TRIGA International, and the fabrication line was moved from California to Romans, France. Currently TRIGA fuel is manufactured in Romans and shipped to the twelve (12) domestic university reactor facilities along with other TRIGA facilities located world-wide.

Per a memorandum dated January 4, 1988, Antoinette Joseph, Office Director of Field Operations, Office of Energy Research provided Don Ofte, Manager, Idaho Operations Office, with definition of the University Reactor Fuel Assistance Program (URFAP). This memo stated that "The URFAP is responsible for fabrication and shipping of nuclear fuel for university research and training reactors. To perform these responsibilities an annual program plan must be developed to include cost and schedule, with technical assistance to be provided by the INEL prime contractor. Program execution guidance and work authorization is provided to the contractor by Idaho Operations Office."

\subsection{National Value of University Reactor Programs}

In 1980, there were sixty-three (63) nuclear research and test reactors, which provide critical handson experience and enable multidisciplinary research. Currently the Research Reactor Operations program supports twenty-four (24) domestic universities that operate a total of twenty-five (25) reactors at their on-campus reactor facilities. On-site reactors, clearly, enhance the educational and research missions of a university. Properly equipped and managed on-campus reactors offer unique advantages in terms of hands-on education and research experience in running small scale experiments which would not be practical at larger off-campus reactors. These on-campus reactors serve a vital national role in both educating and providing experience to nuclear engineers, nuclear scientists, and other professionals critical to our national laboratories, the Department of Energy, the Department of Defense, the Nuclear Regulatory Commission, nuclear power, nuclear medicine, related industries, and Homeland Security. Additionally, the reactor facilities offer tours and information about the reactor facilities and the uses of nuclear energy. In a report of the University Research Reactor Task Force to the Department of Energy Nuclear Energy Research Advisory Committee published in April 2001, the finding was that on-campus reactors have "become a valuable asset as an educational outreach tool for promoting and educating the public about nuclear technologies. These on-campus research reactors contribute to academic values through research, and education and through service to off-campus user constituencies.:

Research: University research reactors are the focus of multi-disciplinary research with contributions to physics, chemistry, biology, medicine, epidemiology, environmental sciences, material sciences, fluid mechanics, geology, archaeology, paleontology, forensic sciences, and other fields in addition to nuclear engineering research and reactor physics. The three principal reactor research techniques are neutron activation analysis, neutron scattering, and neutron radiography. The latter two are largely confined to reactors of one megawatt and higher power. Research reactors in the United States constitute unique and essential research tools in several aspects: structural determinations of materials including superconductors and biologicals, ultra sensitive analysis for traces of elements, radiological display of physical phenomena, and introduction of radioisotopes for medical diagnostics and research.

Education: On-campus reactors have been a traditional focus of educational programs for nuclear engineers. In addition, students in the non-nuclear fields listed above increasingly use on-campus reactors as laboratories. Educational uses are made of even the smallest fractional watt on-campus reactors. Beneficiaries include graduate and undergraduate students, as well as nuclear power plant operators, secondary schools and the general public through outreach programs. 
Service: University reactors, particularly those of one megawatt and larger, serve a range of offcampus constituencies: the medical community, industrial organizations, and government agencies. These clients use irradiated materials, materials analysis, trace element detection, and radiographic analysis of objects and processes. By providing such services, managers of university research reactors establish beneficial links to off-campus users, expose faculty and students to commercial applications of the nuclear sciences, and earn revenue to help support reactor programs."

\subsection{Mission}

The mission of the Research Reactor Infrastructure program is to provide fresh nuclear reactor fuel to domestic universities at no, or low, cost to the university. The title of the fuel remains with the U.S. government and when universities are finished with the fuel, the fuel is returned to the U.S. government. The authority for this program is established under Section 31, Atomic energy Act of 1954, as amended, 42 U.S.C. 2051. See Appendix A for the Memorandum To File, authored by M. Rowan, division of Civilian Nuclear Programs, GC-52, dated May 25, 1996.

\subsection{University Reactor Information}

The RRI program requested input from all supported facilities in order to quantify the capabilities at each facility. Many variations of reactor technology exist within the university operated reactor facilities. The Research Reactor Infrastructure program subcontracts with twenty four (24) University Facilities to supply government owned nuclear fuel for operations. Facilities include twelve (12) TRIGA facilities, eight (8) plate fuel facilities, three (3) AGN facilities; one (1) Pulstar fueled facility, and one (1) critical facility.

Two types of plate fuel are fabricated and used at the reactor facilities, aluminide and silicide. All but two reactors have been converted from Highly Enriched Uranium (HEU) to Low Enriched Uranium (LEU) to conform to the objective of the Global Threat Reduction Initiative (GTRI).

Reactors are licensed and operate at a wide range of powers. The reactor operating at the highest power level and supported by the RRI program is the MURR reactor, which is licensed to operate at 10 mega-watts. Rensselaer Polytechnic Institute (RPI) operates the reactor with the lowest power level at 1 watt. A wide variety of capabilities exist within the university reactor community.

Table 1 contains information for university reactor facilities that are supported by the Research Reactor Infrastructure program. Information contained in the table includes the licensed power rating of the reactor facility, the fuel type of the reactor facility and whether the reactor fuel type is HEU or LEU.

Table 1: Research Reactor Facility Details

\begin{tabular}{|l|l|l|l|}
\hline University & $\begin{array}{l}\text { Reactor } \\
\text { Licensed } \\
\text { Power Level }\end{array}$ & Fuel Type & $\begin{array}{l}\text { Fuel } \\
\text { Details }\end{array}$ \\
\hline University of Missouri - Columbia (MURR) & $10 \mathrm{MW}$ & Aluminide Plate Fuel & HEU \\
\hline Massachusetts Institute of Technology (MIT) & $4.9 \mathrm{MW}$ & Aluminide Plate Fuel & HEU \\
\hline
\end{tabular}




\section{ANNUAL REPORT FOR THE RESEARCH REACTOR INFRASTRUCTURE PROGRAM}

\begin{tabular}{|l|l|l|l|}
\hline Univ. of California - Davis & $2 \mathrm{MW}$ & TRIGA & LEU \\
\hline Rhode Island Nuclear Science Center & $2 \mathrm{MW}$ & Silicide Plate Fuel & LEU \\
\hline Oregon State University & $1 \mathrm{MW}$ & TRIGA & LEU \\
\hline University of Texas at Austin & $1 \mathrm{MW}$ & TRIGA & LEU \\
\hline North Carolina State University & $1 \mathrm{MW}$ & PULSTAR & LEU \\
\hline Penn State University & $1 \mathrm{MW}$ & TRIGA & LEU \\
\hline Texas A\&M University & $1 \mathrm{MW}$ & TRIGA \& AGN & LEU \\
\hline University of Massachusetts at Lowell & $1 \mathrm{MW}$ & Silicide Plate Fuel & LEU \\
\hline University of Wisconsin & $1 \mathrm{MW}$ & TRIGA & LEU \\
\hline Washington State University & $1 \mathrm{MW}$ & TRIGA & LEU \\
\hline Ohio State University & $500 \mathrm{KW}$ & Silicide Plate Fuel & LEU \\
\hline Kansas State & $250 \mathrm{KW}$ & TRIGA & LEU \\
\hline Reed College & $250 \mathrm{KW}$ & TRIGA & LEU \\
\hline University of California at Irvine & $250 \mathrm{KW}$ & TRIGA & LEU \\
\hline University of Maryland & $250 \mathrm{KW}$ & TRIGA & LEU \\
\hline University of Missouri S\&T & $200 \mathrm{KW}$ & Silicide Plate Fuel & LEU \\
\hline University of Florida & $100 \mathrm{KW}$ & Silicide Plate Fuel & LEU \\
\hline University of Utah & $100 \mathrm{KW}$ & TRIGA & LEU \\
\hline Purdue University & $1 \mathrm{KW}$ & Aluminide Plate Fuel & LEU \\
\hline Idaho State University & $5 \mathrm{~W}$ & AGN & LEU \\
\hline University of New Mexico & $5 \mathrm{~W}$ & AGN & LEU \\
\hline Rensselaer Polytechnic Institute & $1 \mathrm{~W}$ & Critical Facility & LEU \\
\hline
\end{tabular}

The primary mission of each university reactor facility is to educate and perform university research. Depending on the capabilities, experimentation activities, and additional missions of each reactor facility, operations may be performed around the clock, or only a couple hours per week.

Table 2 contains operational data for each of the reactor facilities for calendar year 2011 (most recent year end data available). Data includes energy generated in 2011, Average hours per week that the reactor is operated, and grams of U-235 consumed in 2011.

Table 2: Research Reactor Facility Operational Data (Calendar Year 2011)

\begin{tabular}{|l|l|l|l|}
\hline University & $\begin{array}{c}\text { Energy } \\
\text { Generated }\end{array}$ & $\begin{array}{c}\text { Average Hours } \\
\text { Per Week }\end{array}$ & \multicolumn{1}{c|}{$\begin{array}{c}\text { U-235 } \\
\text { Consumed }\end{array}$} \\
\hline University of Missouri - Columbia (MURR) & $78,400 \mathrm{MWH}$ & 149 & $4.12 \mathrm{~kg}$ \\
\hline Massachusetts Institute of Technology (MIT) & $23,688 \mathrm{MWH}$ & 90 & $1.036 \mathrm{~kg}$ \\
\hline
\end{tabular}




\begin{tabular}{|c|c|c|c|}
\hline Univ. of California - Davis & 1,305.29 MWH & 29 & $66.9 \mathrm{~g}$ \\
\hline Rhode Island Nuclear Science Center & $560.62 \mathrm{MWH}$ & 14 & $29 \mathrm{~g}$ \\
\hline Oregon State University & $1,238.0 \mathrm{MWH}$ & 28 & $74 \mathrm{~g}$ \\
\hline University of Texas at Austin & 381.9 MWH & 22 & $12 \mathrm{~g}$ \\
\hline North Carolina State University & 4,261.47 MWH & 85 & $210 \mathrm{~g}$ \\
\hline Penn State University & $603.97 \mathrm{MWH}$ & 39 & $31.1 \mathrm{~g}$ \\
\hline Texas A\&M University & 2,078.4 MWH & 41 & $117 \mathrm{~g}$ \\
\hline University of Massachusetts at Lowell & $95 \mathrm{MWH}$ & 8 & $4.93 \mathrm{~g}$ \\
\hline University of Wisconsin & $434.31 \mathrm{MWH}$ & 11 & $22.6 \mathrm{~g}$ \\
\hline Washington State University & 1,140.9 MWH & 21.9 & $58 \mathrm{~g}$ \\
\hline Ohio State University & $96.20 \mathrm{MWH}$ & 11 & $4.9 \mathrm{~g}$ \\
\hline Kansas State & $57.0 \mathrm{MWH}$ & 10 & $3.0 \mathrm{~g}$ \\
\hline Reed College & $65.59 \mathrm{MWH}$ & 5 & $3.41 \mathrm{~g}$ \\
\hline University of California at Irvine & $18.35 \mathrm{MWH}$ & 3 & $0.96 \mathrm{~g}$ \\
\hline University of Maryland & $12.02 \mathrm{MWH}$ & 8 & $0.68 \mathrm{~g}$ \\
\hline University of Missouri S\&T & 19.8 MWH & $\begin{array}{l}10 \text { in summer } \\
25 \text { during } \\
\text { semesters }\end{array}$ & $1.0 \mathrm{~g}$ \\
\hline University of Florida & $0^{*}$ & $0 *$ & $0^{*}$ \\
\hline University of Utah & $6.02 \mathrm{MWH}$ & 3 & $<0.01 \mathrm{~g}$ \\
\hline Purdue University & $1.36 \mathrm{kWH}$ & 2 & $0.00007 \mathrm{~g}$ \\
\hline Idaho State University & $0.312 \mathrm{kWH}$ & 4 & 50 micrograms \\
\hline University of New Mexico & $0.315 \mathrm{kWH}$ & 5 & 390 micrograms \\
\hline Rensselaer Polytechnic & 0.786 & 5 & 4 micrograms \\
\hline
\end{tabular}

* The University of Florida has been undergoing extensive maintenance activities and did not operate during 2011.

Although the major focus of all university reactor facilities is to educate and perform university research, many also provide commercial services such as isotope production for medical and industrial use. All missions are executed concurrently and no reactor facilities are operated solely to perform commercial work. Most on-site university research reactors offset operating costs by charging industrial users and commercial industry for neutrons and products provided. All funding derived from these sources are used to subsidize and maintain operability of the reactor facilities and if these additional funding sources were not available to the reactor facilities, the reactor directors indicated that the reactors face a high risk of being shut down due to lack of operational funding provided by their respective universities. 


\section{ANNUAL REPORT FOR THE RESEARCH REACTOR INFRASTRUCTURE PROGRAM}

Page: 6 of $\mathbf{1 3}$

Table 3 contains reactor usage data for each of the reactor facilities for calendar year 2011 (most recent year end data available). Data includes percentage of fuel usage for five categories of operations. These include: Instruction and Training, University Research, Academic \& Industrial Research for facilities other than the sponsoring university, calibration and maintenance activities, and isotope or other products generated and sold to outside industry.

Table 3: Research Reactor Facility Usage Data (Calendar Year 2011)

\begin{tabular}{|c|c|c|c|c|c|}
\hline University & $\begin{array}{l}\text { Instruction } \\
\text { and } \\
\text { Training }\end{array}$ & $\begin{array}{l}\text { University } \\
\text { Research }\end{array}$ & $\begin{array}{c}\text { Academic } \\
\text { and } \\
\text { Industrial } \\
\text { Research }\end{array}$ & $\begin{array}{c}\text { Calibration } \\
\text { and } \\
\text { Maintenance }\end{array}$ & $\begin{array}{l}\text { Commercial } \\
\text { Industry }\end{array}$ \\
\hline $\begin{array}{l}\text { University of Missouri - } \\
\text { Columbia (MURR) }\end{array}$ & $\begin{array}{l}\text { To Be } \\
\text { Determined }\end{array}$ & $\begin{array}{l}\text { To Be } \\
\text { Determined }\end{array}$ & $\begin{array}{l}\text { To Be } \\
\text { Determined }\end{array}$ & $\begin{array}{l}\text { To Be } \\
\text { Determined }\end{array}$ & $\begin{array}{l}\text { To Be } \\
\text { Determined }\end{array}$ \\
\hline $\begin{array}{l}\text { Massachusetts Institute of } \\
\text { Technology (MIT) }\end{array}$ & $10 \%$ & $40 \%$ & $15 \%$ & $20 \%$ & $15 \%$ \\
\hline Univ. of California - Davis & $0 \%$ & $50 \%$ & $50 \%$ & $0 \%$ & $0 \%$ \\
\hline $\begin{array}{l}\text { Rhode Island Nuclear } \\
\text { Science Center }\end{array}$ & $40 \%$ & $30 \%$ & $30 \%$ & $5 \%$ & $0 \%$ \\
\hline Oregon State University & $2 \%$ & $18 \%$ & $51 \%$ & $19 \%$ & $10 \%$ \\
\hline $\begin{array}{l}\text { University of Texas at } \\
\text { Austin }\end{array}$ & $25 \%$ & $55 \%$ & $20 \%$ & $0 \%$ & $0 \%$ \\
\hline $\begin{array}{l}\text { North Carolina State } \\
\text { University }\end{array}$ & $56 \%$ & $<2 \%$ & $40 \%$ & $2 \%$ & $0 \%$ \\
\hline Penn State University & $18 \%$ & $20 \%$ & $44 \%$ & $18 \%$ & $0 \%$ \\
\hline Texas A\&M University & $27 \%$ & $15 \%$ & $15 \%$ & $5 \%$ & $38 \%$ \\
\hline $\begin{array}{l}\text { University of Massachusetts } \\
\text { at Lowell }\end{array}$ & $37 \%$ & $44 \%$ & $16 \%$ & $3 \%$ & $0 \%$ \\
\hline University of Wisconsin & $90 \%$ & $2 \%$ & $3 \%$ & $5 \%$ & $0 \%$ \\
\hline $\begin{array}{l}\text { Washington State } \\
\text { University }\end{array}$ & $50 \%$ & $25 \%$ & $10 \%$ & $10 \%$ & $5 \%$ \\
\hline Ohio State University & $20 \%$ & $35 \%$ & $43 \%$ & $3 \%$ & $0 \%$ \\
\hline Kansas State & $34 \%$ & $43 \%$ & $0 \%$ & $23 \%$ & $0 \%$ \\
\hline Reed College & $60 \%$ & $30 \%$ & $0 \%$ & $10 \%$ & $0 \%$ \\
\hline $\begin{array}{l}\text { University of California at } \\
\text { Irvine }\end{array}$ & $27 \%$ & $54 \%$ & $11 \%$ & $8 \%$ & $0 \%$ \\
\hline University of Maryland & $20 \%$ & $70 \%$ & $0 \%$ & $10 \%$ & $0 \%$ \\
\hline University of Missouri S\&T & $95 \%$ & $5 \%$ & $0 \%$ & $0 \%$ & $0 \%$ \\
\hline University of Florida & $100 \%$ & $0 \%$ & $0 \%$ & $0 \%$ & $0 \%$ \\
\hline University of Utah & $60 \%$ & $30 \%$ & $0 \%$ & $10 \%$ & $0 \%$ \\
\hline Purdue University & $83 \%$ & $17 \%$ & $0 \%$ & $0 \%$ & $0 \%$ \\
\hline
\end{tabular}




\begin{tabular}{|l|l|l|l|l|l|}
\hline Idaho State University & $90 \%$ & $10 \%$ & $0 \%$ & $0 \%$ & $0 \%$ \\
\hline University of New Mexico & $100 \%$ & $0 \%$ & $0 \%$ & $0 \%$ & $0 \%$ \\
\hline Rensselaer Polytechnic & $80 \%$ & $0 \%$ & $0 \%$ & $20 \%$ & $0 \%$ \\
\hline
\end{tabular}

Appendix B contains information provided by the universities affiliated with the RRI program. Each university overview contains a brief history of the reactor facility, the mission of the reactor, products provided and customers supported by the reactor facility, and any special capabilities that make the facility unique or different from the other university reactor facilities.

\section{PROJECT ACCOMPLISHMENTS DURING FISCAL YEAR 2012}

This section of the report identifies project accomplishments completed during FY-12. These accomplishments are divided into the following sub-sections: 3.1) Fuel Fabrication and Delivery to Universities, 3.2) Spent Fuel Shipments, 3.3) Project Management and Technical Support, and 3.4) Miscellaneous Accomplishments

\subsection{Fuel Fabrication and Delivery to Universities}

The following fresh fuel deliveries were made to universities during Fiscal Year 2012.

- Twenty four (24) fresh fuel elements were delivered to the MURR facility.

- Nine (9) fresh fuel elements were delivered to the MIT facility. Eighteen (18) fresh fuel elements were planned for shipment in FY-12, but nine (9) fuel elements scheduled for shipment were cancelled per the University's request. The fuel elements will be maintained in the Babcock and Wilcox inventory and shipped to MIT at a later date. Several activities led up to the University requesting the cancellation of these shipments. These include:

- Completion of all DOE-sponsored in-core experiments by the end of June 2012.

- Unanticipated reduction of other neutron irradiation demands.

- MIT reactor management made the decision to de-fuel the fission converter facility for maintenance. Nine of the eleven partially-irradiated elements from the fission converter tank will be used for reactor refueling activities.

- Four (4) fresh fuel elements were delivered to the Rhode Island Nuclear Science Center (RINSC) facility.

\subsection{Spent Fuel Shipments}

The following spent fuel shipment activities were completed during Fiscal Year 2012.

- Thirty-two (32) spent fuel elements were shipped from the University of Missouri Research Reactor (MURR) to the DOE Receipt Facility located at the Savannah River Site. 
- Sixteen (16) spent fuel elements were shipped from Massachusetts Institute of Technology (MIT) to the DOE Receipt Facility located at the Savannah River Site.

- Conversations and pre-planning have been initiated with Penn State University (PSU) and the University of Texas (UT) for a joint spent fuel shipment scheduled for FY-13. Preliminary work scope includes preparation and approval of the Required Shippers Data (RSD) forms, and kick-off meetings at the facilities. Attendees at the kick-off meetings included representatives from the reactor facilities, the Department of Energy Idaho Field Office, the RRI Project Manager, and representatives from NAC International, and Secured Transportation Services (STS). The NAC LWT cask will be leased to perform the spent fuel shipment. NAC personnel will be contracted to load the cask, and STS personnel will coordinate shipment activities including transportation, security escort services, and required notification activities.

\subsection{Project Management and Technical Support}

The following Project Management and Technical Support activities were completed during Fiscal Year 2012.

- The Idaho National Laboratory maintained current and updated fuel support contracts with the twenty-four domestic universities that operate reactor facilities. These contracts document government ownership of reactor fuel, usage, and reporting requirements. Maintenance of these contracts is important to DOE and the RRI Program as these are the contractual agreements that implement the Atomic Energy Act Sections 31 and 53 for the receipt and use of DOE owned reactor fuel.

- The RRI program has worked closely with personnel at all supported reactor facilities to update inventory reports. Additional information gathered included fresh fuel and spent fuel anticipated needs for the next five years. This information is important to DOE and the RRI Program as it will be used to prioritize fresh fuel procurement prioritization activities and spent fuel shipment support.

- A contract has been awarded to AREVA Federal Services to supply spare (consumable) parts for the BEA Research Reactor (BRR) spent fuel shipping container. Spare parts include drain and vent port seals, replacement drain ports and vent port fasteners, spare leak test tool, adapter kit and impact limiter ball lock pins. The procurement of these consumable parts is important to DOE and the RRI program as they are required for each shipment of spent fuel using the BRR cask.

- The RRI program has contracts with General Atomics and the Colorado School of Mines to perform reactor modeling as part of relicensing activities for the University of California - Irvine, the University of Maryland, and Purdue University. The modeling results are used to support responses to Requests for Additional Information (RAI's) from the Nuclear Regulatory Commission (NRC). The implementation of these contracts was based on an interoffice 
agreement between DOE and the NRC for the RRI program to support the relicensing activities of these reactors. As such completion of this work scope is important to DOE and the RRI program.

- Eight TRIGA fuel elements were fabricated for the reactor facility operated by the University of California at Davis (UC-Davis) in 2007. The fabrication contract did not have a provision for recycling the scrap for uranium recovery. A Request for Proposal was submitted to TRIGA International for scrap recycling in FY-12. Upon completion of this subcontracted work, 2.8 kilograms of uranium metal will be added back into the RRI managed uranium stockpile held for TRIGA fuel fabrication. This work-scope is important to DOE and the RRI program as this will complete the TRIGA fuel fabrication activity, and also add to the uranium stockpile for future TRIGA fuel fabrication activities.

- In FY-12, MURR was invoiced for 20 fresh fuel elements delivered during FY-11 in accordance with a contractual agreement between DOE-ID and the University of Missouri, (Contract \# DESC07-78D01723, which established a cost share of $\$ 4,000$ per element. This subcontract was put in place to address potential perceptions of government assistance to a university competing with commercial industry in the production and distribution of medical isotopes. The INL invoices MURR on an annual basis for the fuel elements delivered and accepted during the previous fiscal year. These funds are then used to support program activities as agreed upon between the RRI program and DOE either through fiscal year planning activities, or implementation of the Baseline Change Proposal (BCP) process. This activity is important to DOE and the RRI program as it annually implements the contractual agreement between DOE and the University of Missouri, and also as it provides an additional funds source for the RRI program.

\subsection{Issues / Opportunities}

The following Issues and Opportunities for project improvements were addressed during Fiscal Year 2012.

- An amendment request was approved by the Nuclear Regulatory Commission (NRC) to modify the Advanced Test Reactor (ATR) Fresh Fuel Shipping Container (FFSC) Certificate of Compliance. The ATR FFSCs are used to ship fresh fuel from the fuel fabrication facility (Babcock and Wilcox) to the University of Missouri Research Reactor (MURR), the Massachusetts Institute of Technology (MIT) and Rhode Island Nuclear Science Center (RINSC). The amendment included the addition of payloads for small quantities and the modification to the existing payloads to correct water channel gap dimensions for MURR, MIT, and RINSC fuel types. This is important to DOE and the RRI program as it ensures all plate fuel fabricated for these facilities that meets all acceptance requirements can be shipped to the universities for use.

- The TRIGA fuel fabrication line in Romans, France is currently shut down to perform maintenance and security upgrades. It is anticipated that TRIGA International will not enter contracts for new fuel element fabrication until Fiscal Year 2014 and that fuel elements will not be deliverable to reactor facilities until Fiscal Year 2015 at the earliest. There is still low to 
moderate risk that the fabrication line will not restart. The RRI program is evaluating the impact that this will have on the domestic university reactor facilities. In the event the fabrication line does not restart operations, one option available to the RRI program is to use the BRR spent fuel shipping container to move lightly irradiated fuel between reactor facilities as needed to keep the facilities operational for as long as possible. In order to use the BRR container to move fuel elements between reactor facilities, a dry transfer system has been designed. The RRI program has requested the assistance of the INL Packaging and Transportation (P\&T) department to organize a Design Review Team and perform the formal design review. P\&T has received all of the design documents and is organizing the team. The decision has been made by P\&T that the cask designer (AREVA Federal Services) should be included on the design review team to evaluate loads on the cask, etc. The design review is expected to be completed early in FY-13, changes to be design will be made if necessary, and the dry transfer system will be fabricated in FY-13. This is important to DOE and the RRI program as it provides alternative options for fuel transfers between facilities in the event that fresh fuel elements are not available from TRIGA International. This also decreases the risk that a university reactor facility with shut down due to a lack of fuel availability.

- GE Hitachi announced that starting July 1, 2012 it would no longer be leasing any of its Type A or type B casks or transport containers, including the GE Model 2000 cask. This has resulted in increased interest from other INL programs and DOE operated facilities for potential use of the BRR cask to support their missions. It is recommended that DOE and INL evaluate the sharing and future use of the cask by programs other than the RRI program. There are costs associated with its use (wear and tear, and maintenance). All seals and o-rings must be replaced for each shipment of the cask, with costs incurred to replace the seals and o-rings. An adequate quantity of these spare parts is budgeted each fiscal year for routine RRI shipments, but if the cask is used for additional shipment activities, additional costs will be incurred to maintain an inventory of spare parts. This is important to DOE and the RRI program because the interest in the use of the cask may result in increased costs to maintain the cask in the future as consumable supplies of o-rings and seals will be needed for each shipment using the cask.

- The Fuel Fabrication Capabilities (FFC) program which is part of the Reduced Enrichment for Research and Test Reactor (RERTR) group has received a contract proposal from Babcock and Wilcox $(B \& W)$ for the purchase and placement of rolling mills for the Limited Production Facility for the fabrication of U-Moly fuel elements. This equipment must be located in the "hot area" at B\&W. Space availability in the "hot area" is very limited. In order to make space, B\&W has indicated that they will need to tear out and dispose of the LEU fuel powder and compacting lines. The only current mission left for this equipment is the fabrication of Rhode Island fuel elements. Rhode Island has indicated that 12 additional fuel elements will be needed to maintain adequate fuel inventory for the anticipated 20 year remaining life of the reactor facility. This request to remove the product line was brought to the attention of the DOE-ID Program Manager over the RRI program. DOE-NE and DOE-NNSA came to an agreement that due to DOE-NE funding constraints, DOE-NNSA will fund the fabrication of the twelve Rhode Island elements, 
and be reimbursed by DOE-NE at a later date. Tear out of the fuel compact line will not take place until adequate fuel plates are fabricated for the remaining twelve fuel elements. B\&W is not able to store the fuel plates due to space constraints, so the fuel elements will be completed as part of the process. It is anticipated that the fuel elements will be fabricated during FY-13. This is important to DOE and the RRI program since the agreement between DOE-NE and DOENNSA includes the agreement that the costs will be reimbursed at a later date. This will either require the DOE-NE request additional funding to reimburse these costs, or the RRI program will have less funding available to complete work scope when the reimbursement is made.

\subsection{Other Activities}

The following other activities are Project Managements tasks completed to support RRI program and ensure success in meeting the mission of the program.

- The RRI project Manager presented the Program Status Report at the annual Test Research Training Reactor (TRTR) Conference. Attendees included representatives from the university reactor facilities, National Laboratories, the Department of Energy, and the Nuclear Regulatory Commission. Attendance and presentation at the annual TRTR conference is important to DOE and the RRI program as this is an opportunity to meet with representatives of all the reactor facilities to address concerns and to update the reactor community as a whole as to the status and future plans for the RRI program.

- The RRI Project Manager was invited by the University of Utah reactor director to perform a site visit and to present a University Nuclear Education Program (UNEP) seminar for undergraduate and graduate students. During the visit discussions were held regarding current education and reactor usage plans. The University of Utah reactor director also invited the RRI program manager to serve as a member of the Industrial Advisory Board for the Utah Nuclear Engineering Program (UNIAB). This is important to DOE and the RRI program as it give the opportunity to work directly with supported universities and to interface directly and educate students in the Nuclear Engineering field.

\section{BUDGET SUMMARY}

The INL RRI program budget for FY-12 was $\$ 4,672,175$. At year-end the Budgeted Cost of Work Performed (BCWP) was $\$ 4,417,925$. The Actual Cost of Work Performed (ACWP) was $\$ 4,613,987$. This resulted in a Schedule Performance Index (SPI) of 0.95 and a Cost Performance Index (CPI) of 0.96.

Planned work-scope that was not completed in FY-12 included the fabrication of the BRR Cask Dry Transfer System. Due to delays in the design phase of the BRR cask dry transfer system, the Formal Design Review is being performed in FY-13. It is anticipated that the dry transfer system will be fabricated in FY-13. Approximately fifty six percent (56\%) of the funding that was budgeted for the fabrication of the dry transfer system was reallocated through agreement between INL management and DOE-NE for Materials and Fuels Complex (MFC) Corrective Action Support. The total amount that was 
transferred from the RRI Program for MFC Corrective Action Support in August and September was $\$ 141,431$.

Figure 1 shows FY-12 Cost and Schedule Performance for the RRI Program. As shown in the chart, program costs and schedules had minimal variance for each month and remained below the $10 \%$ reporting threshold established by DOE.

Figure 1: FY-12 Cost and Schedule Performance

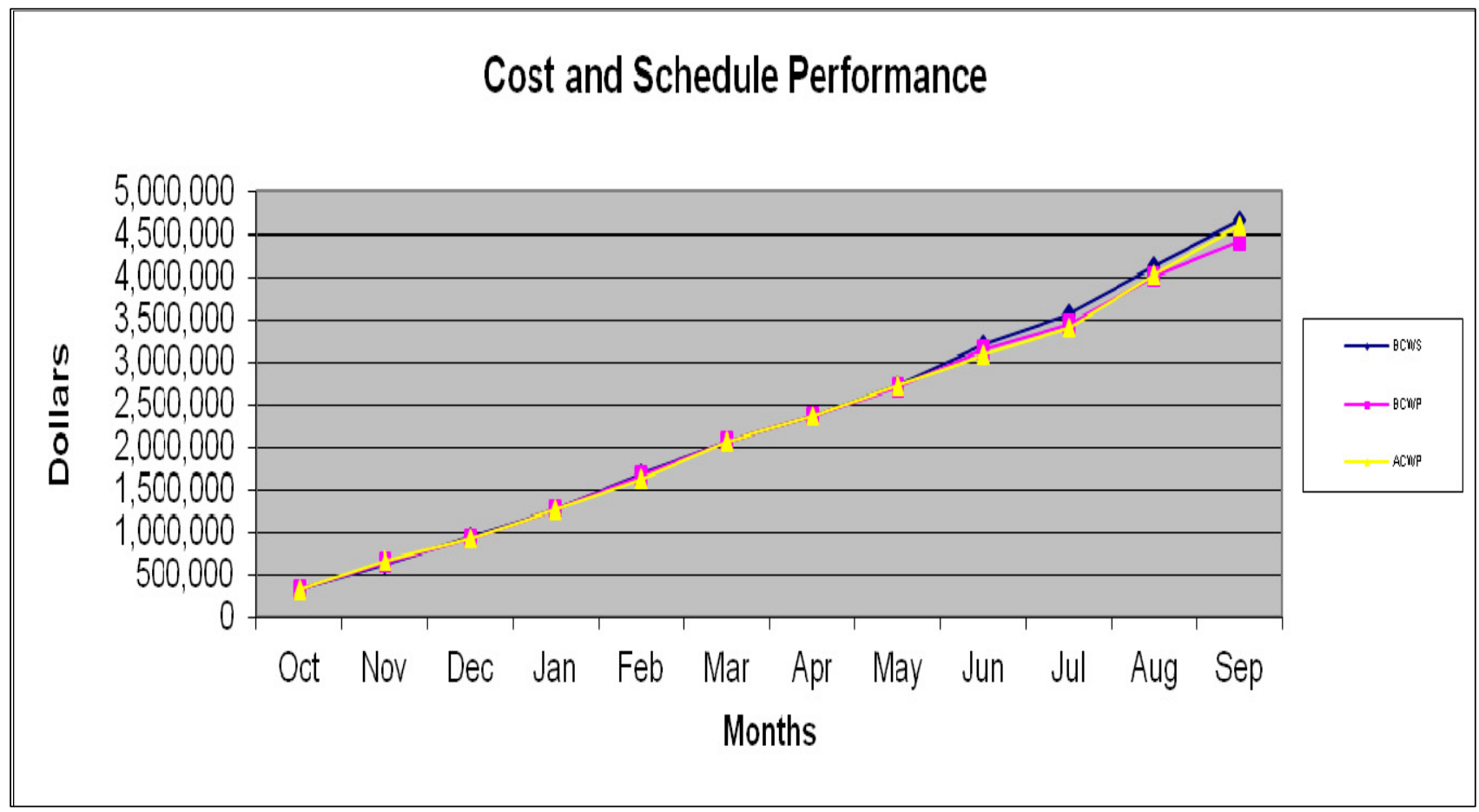

\section{CONCLUSIONS}

With the exception of the fabrication of the BRR Cask dry transfer system and the cancellation of fresh fuel shipments to MIT, all planned activities and milestones were completed on or ahead of schedule and at or under cost.

The mission of the RRI program was met for FY-12. Sufficient fuel elements were fabricated and delivered to the university research reactors to maintain sustained operability of all supported reactor facilities. Spent fuel elements were returned to the DOE owned receipt and storage facility at Savannah River Site, thus maintaining a minimal supply of Special Nuclear Material (SNM) at university facilities.

Operational data received from the university reactor facilities indicate that regardless of pervasive funding constraints at each reactor facility, Nuclear Education and Research programs continue to operate, and many are seeing expansion and growth. 


\section{Appendix A}

\section{Memorandum to File - M. Rowan}

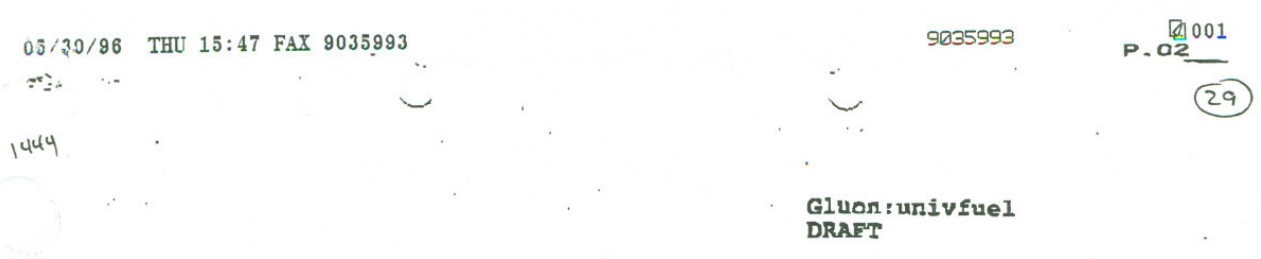

May 25, 1996

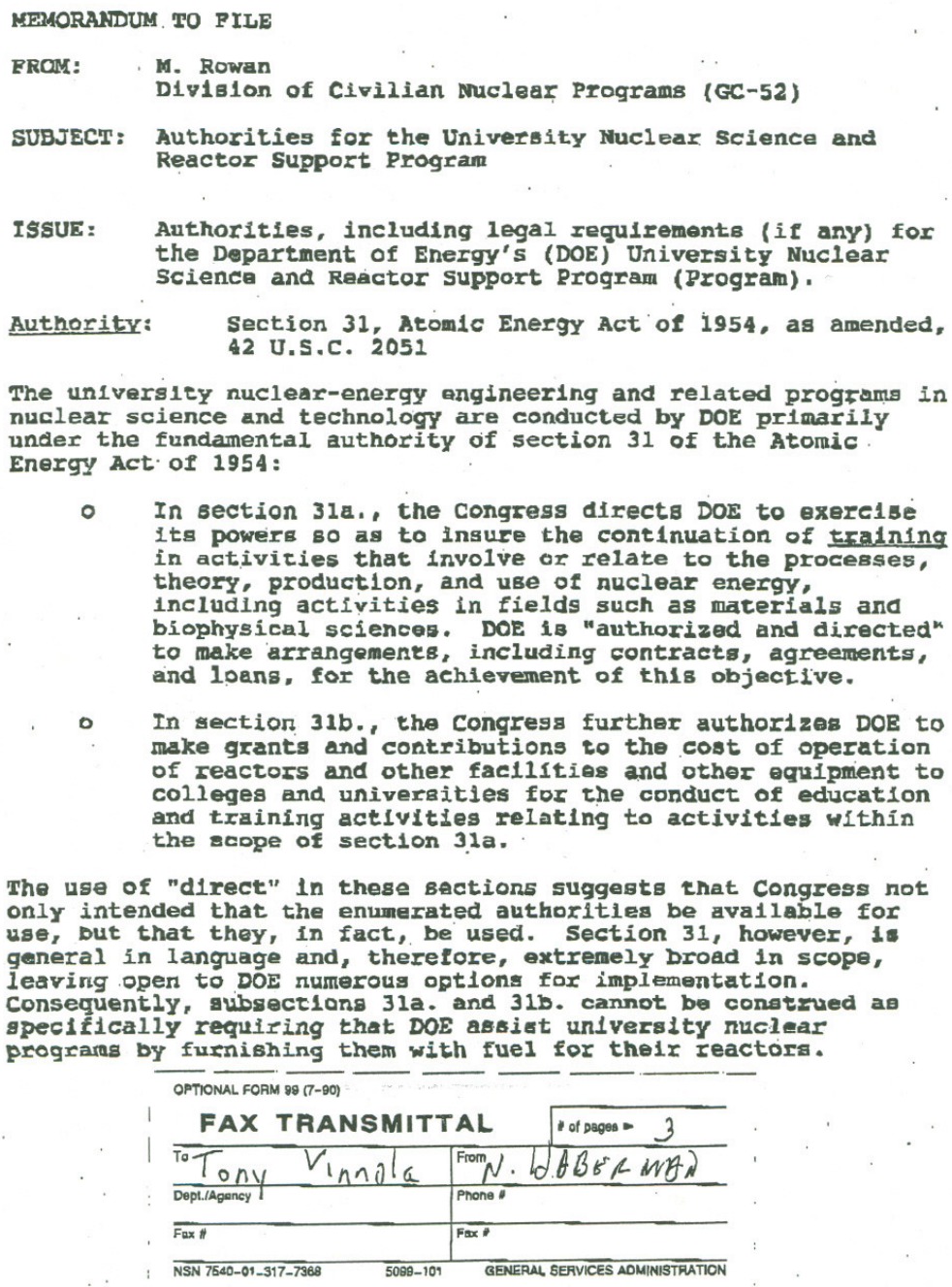

The university nuclear-energy angineering and related programs in nuclear science and technology are conducted by DOE primarily under the fundamental authority of section 31 of the Atomic Energy Act of 1954:

- In section 31a., the Congress directs DOE to exercise its powers so as to insure the continuation of training in activicies that involve or relate to the processes, theory, production, and use of nuclear energy, including activities in fields such as materíals and biophysical sciences. DOE IB "authorized and directed" to make arrangements, including contractg, agreements, and loans, for the achievement of this objective.

- In section 31b., the Congress further author1zes DOE to make grants and contributions to the cost of operation of reactors and other faclifties and other equipment to colleges and universities for the conduct of education and trainigg activities relating to activities within the scope of section $31 \mathrm{a}$.

The use of "direct" In these sections suggests that Congress not only intended that the enumerated authorities be avallable for use, Dut that they, in fact, be used. Section 31 , however, is general in language and, therefore, extremely broad in scope, leaving open to DOE numerous options for implementation. Consequently, aubsectlons $31 \mathrm{a}$. and $31 \mathrm{~b}$. cannot be construed as gpecifically requiring that $D O E$ assist unlversity nuclear prograras by furnishing them with fuel for their reactors.

\begin{tabular}{|c|c|c|c|}
\hline FAX & TRANSMIT & AL & i of Dages = 3 \\
\hline Tony & $V_{\text {innola }}$ & ${ }^{\text {From }} \mathrm{N}$. & $\partial \overline{A B G}(\overline{W B})$ \\
\hline Dept./Agency T & & Prone o- & \\
\hline Fax \# & & Fax" & \\
\hline
\end{tabular}




\section{ANNUAL REPORT FOR THE RESEARCH REACTOR INFRASTRUCTURE PROGRAM}

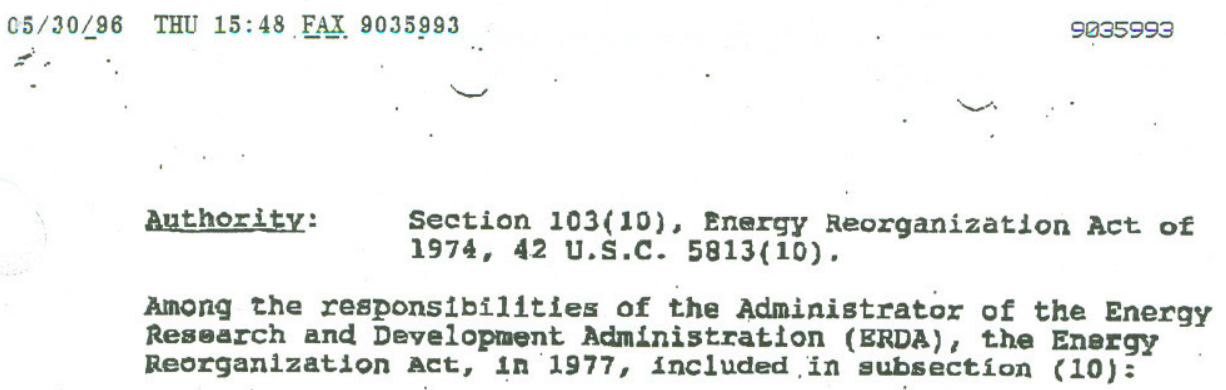

Anong the responsibilities of the Administrator of the Energy Research and Development Administration (BRDA), the Energy Reorganization Act, in 1977, included, in subsection (10):

[H]elping to assure an adequate supply of manpower for the accomplishment of energy research and development prograris, by sponsoring and assisting in education and training activities in institutions of higher education....

Although expressed in more finita terms, this provision describes an authority that is to be implemented at the Administrator's (now DOE's) discretion.

Authority: The education-assistance authorities of the ERDA Administrator were transferred to the Secretary of Energy by operation of section 301 (a) af the Department of Energy Organlzation Act of 1977,42 U.S.C. 7151 (a), but the Act added no legal requirements specifically for research-reactor fuel assistance.

Belated Authorities: The following statutes relating to university-level educational activitles of DOE were examined for provisions of potential relevance to the Program: None were found that explicitly or implicitly impose an obligation upon DOE to furnish fuel for university reactors:

i.

The Department of Energy science Education Enhancenent Act, Public Law 10l-510, Part E (Nov. 5, 1990), which authorizes a number of science-education activities by DOE, many of which involve the use of National Laboratory resources.

The Excellence in Mathematics, Science and Engineering Act, Public Law 101-589 (Hov. 16, 1990), a broad-scope gtatute auchorizing a number of incentives designed to enhance sclence and technical education in the Unired states.

The Energy and Pater Development Appropriations Act for Fiscal Year 1991, Public Law 101-514, section 305 (Nov. 5, 1990), a substantive provision permitting funds appropriated to DOE to be used in carrying out programs in improvement of science and engineering education and skills with the objective of ensuring that a continuing supply of technical and scientific workers is avallable to accomplish U.S. national energy and energy security misgions.

- The Energy Policy Act of 1992, Public Law 102-486, section 2203 (b) (Oct. 24, 1992), which reguires a program for the improvement and upgrading of university research reactors and associated instrumentation and equipment, but 1mposes no requirements regarding DOE's provision of fuel for these reactors. 
05/30/96_THU $15: 48$ FAX 9035993

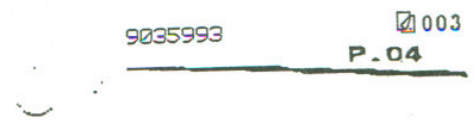

$=-2$

- Various Energy and water Development Appropriations Acts, Including the Act for piscal Year 1996, Public Law 104-46. Title III (Nov. 13, 1995), to determine whether lino-1tems are or have been used to require specific expenditures in support of Program activities.

Conclusion: Barring future line-iten appropriations or the amendment of current general law, there appear to be no. statutory proyisions that would legally obligate DOE to epeciflcally provide fuel to universities for the operation of their research/training reactors. 


\section{ANNUAL REPORT FOR THE RESEARCH REACTOR INFRASTRUCTURE PROGRAM}

\section{University of Missouri - Columbia (MURR)}

The University of

Missouri Research Reactor (MURR) is a multi-disciplinary research, development and education center operated by the University of MissouriColumbia (MU). With its first start-up on October 13, 1966, the reactor has been in operation for more than 40 years. A $100 \%$ power upgrade from 5 to $10 \mathrm{MW}$ was performed in 1974 and a more than $50 \%$ increase in

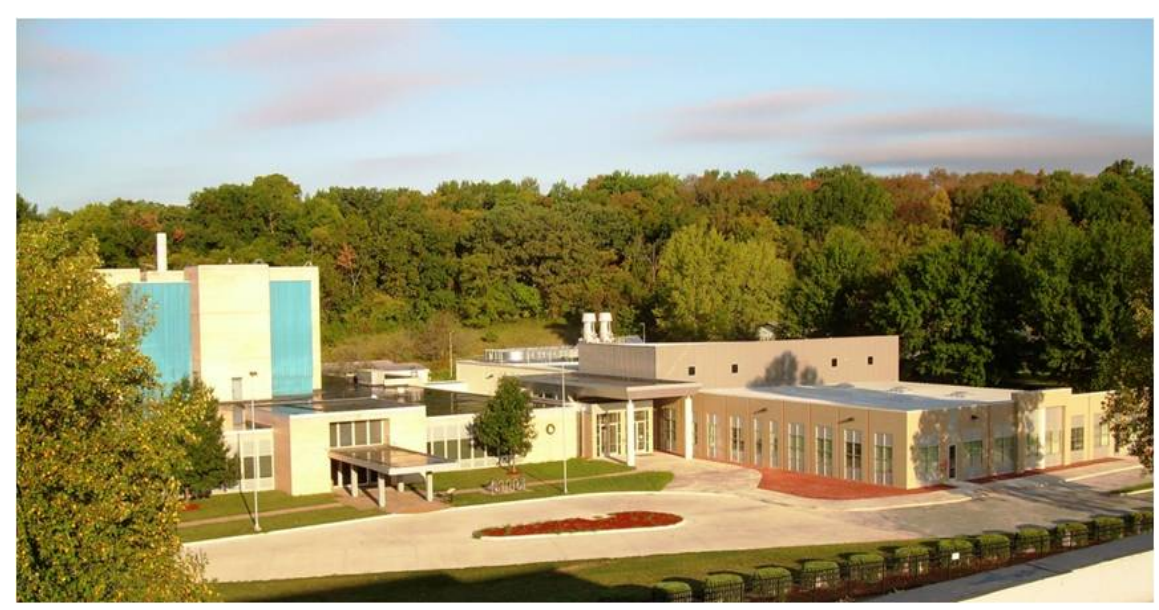
operating hours in 1977 allow the reactor to maintain a 150+ hours per week schedule. The 10 MW light water moderated and cooled reactor is versatile and compact in design, with a peak unperturbed thermal neutron flux of $6 \mathrm{E} 14 \mathrm{n} / \mathrm{cm}^{2}$-s and a peak fast flux of $1 \mathrm{E} 14 \mathrm{n} / \mathrm{cm}^{2}$-s in the flux trap, and its enviable operating record allows multiple irradiations and experiments virtually around the clock. Safety at the MURR holds the highest operational priority, and its solid record of safe operation is owing to a combination of meeting stringent NRC-directed safety regulations, employing a high-quality technical and operations staff, and endorsing a philosophy of proactive, corrective and preventive maintenance. The MURR is recognized worldwide as the single most productive university-operated research reactor, in large part because of its reliable operating schedule, concise reactor design and wide-ranging, interdisciplinary research, education and development programs.

This is in keeping with the MURR's three-fold mission of research, education and service. Of particular importance are interdisciplinary Research \& Development programs with partnering MU departments, other universities, federal and industrial labs - programs that could not be conducted without the unique MURR facilities and personnel. The MURR provides leverage for the expertise and talents resident in other departments and institutions, and a keen focus is on collaborative research programs in the life sciences with potential to lead to breakthroughs in healthcare.

The University and private collaborators have developed, patented and commercialized three FDA-approved radiopharmaceuticals: Ceretec $^{\mathrm{TM}}$, the first radiopharmaceutical to image the brain effectively to diagnose and assess stroke victims and now also used to locate infection; TheraSphere ${ }^{\mathrm{TM}}$ to treat liver cancer; and Quadramet ${ }^{\circledR}$, which relieves the debilitating pain associated with metastatic bone cancer. With its unique collection of resources - the MURR; School of Medicine and its Ellis Fischel Cancer Hospital; College of Veterinary Medicine; and College of Agriculture, Food and Natural Resources; and neighboring Harry S Truman Veterans Administration Hospital-MU is actively developing new medical technologies through translational and comparative research. A sampling of other R\&D programs involve nanotechnologies, materials analyses, nuclear battery development, semiconductors, biomembranes, environmental analyses, epidemiology, boron neutron capture therapy and international databases with applications in archaeology, anthropology and geology.

The MURR provides rich research and training opportunities for an international population of undergraduate, graduate and postdoctoral students in such disciplines as anthropology, archaeology, chemistry, engineering (chemical, electrical, mechanical and nuclear), geology, materials science, medical and life sciences (including cancer diagnostics, treatment and prevention), nutrition, physics and veterinary medicine, and is active in producing technicians in the nuclear medicine and power industries. 
Over the past several years MURR staff worked systematically through its Renewal and Relicensing Program (R\&R), completing tasks fundamental to its license renewal for an additional 20 years of safe and productive operation, submitted in 2006. The R\&R program involved modernizing key equipment and structures and upgrading to meet revised health and safety codes. Federal endorsement of the $\mathrm{R} \& \mathrm{R}$ efforts is evident in significant funding received from the Department of

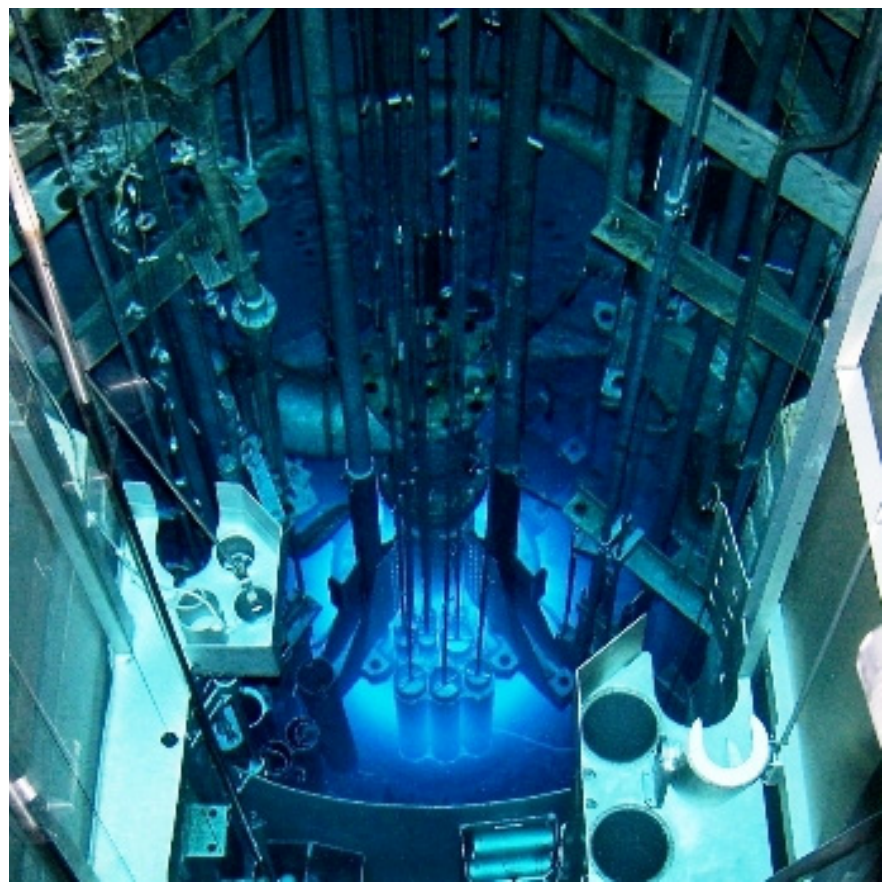
Energy to support key aspects.

With its reliable operating schedule, custom facilities and instrumentation and expertise in processing and regulatory compliance, the MURR routinely provides research and commercial isotopes to a global community, in some cases is the nation's sole provider of products and services that directly result in treatments to cancer patients. In recent years MURR built from scratch an FDA-compliant cGMP (current Good Manufacturing Practices) program encompassing quality systems, infrastructure, staff and expertise to bring pharmaceutical grade radiochemicals, drug products and analyses to its roster of products and services. The $16 \mathrm{MeV}$ cyclotron housed at MURR (owned and operated by Essential Isotopes, LLC) produces a complementary set of positron-emitting isotopes for regional research and patient applications. 


\section{ANNUAL REPORT FOR THE RESEARCH REACTOR INFRASTRUCTURE PROGRAM}

\section{Massachusetts Institute of Technology}

The MIT Nuclear Reactor Laboratory (NRL), which has served the university and surrounding community for 52 years, is an interdepartmental center that operates a $5 \mathrm{MW}$ research reactor in support of MIT's educational and research initiatives and goals. The reactor, which is designated as the MITR-II, is the second of two research reactors that have been operated by the NRL. The original reactor (the MITR-I) achieved criticality in 1958. In 1973, the MITR-I was shut down to allow conversion to the MITR-II, which offered a higher neutron flux level. On 8 July 1999, a formal

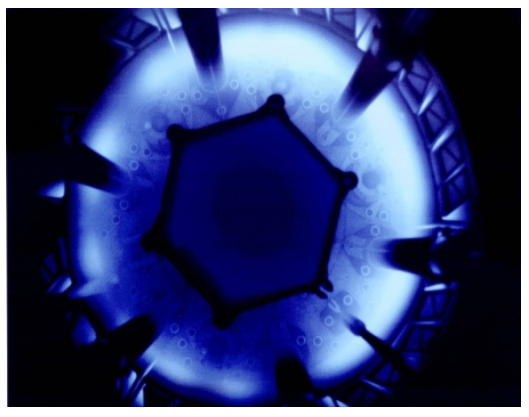
application was submitted to the U.S. Nuclear Regulatory Commission (NRC) to relicense the reactor for an additional twenty years and to upgrade the power level to $6 \mathrm{MW}$. The new license is expected to issue fall of 2010. The reactor design has the capability of running at $10 \mathrm{MW}$. Research funded under DOE's Reduced Enrichment for Research and Test Reactors (RERTR) Program is on-going at the NRL and will eventually enable the MITR-II to be converted from High Enriched Uranium (HEU) to Low Enriched Uranium (LEU) fuel.

The NRL's mission is to provide faculty and students from MIT as well as the national scientific and engineering community with both a state-of-the-art reactor facility and the infrastructure to enable and support its use for research and other societal objectives. Highest priority is placed on operating the research reactor in a highly professional manner that is safe to MIT and NRL staff, researchers, the public, as well as the environment. The NRL is also committed to educating the general public by promoting education and training in nuclear sciences and technologies.

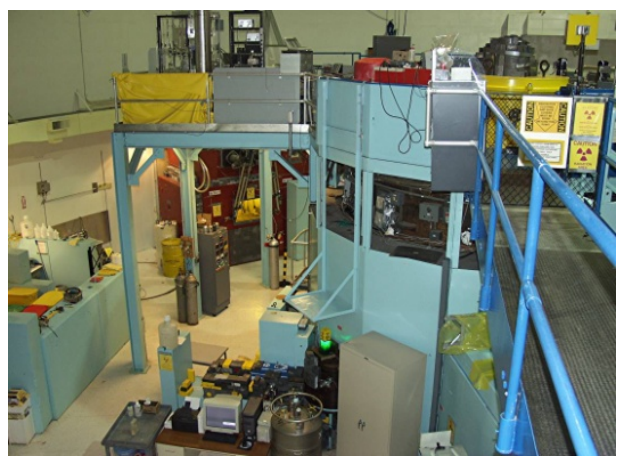

The MITR-II is the major experimental facility of the NRL. It is a heavy-water reflected, light-water cooled and moderated nuclear reactor that utilizes flat, plate-type, finned, aluminum-clad fuel elements. The average core power density is about $70 \mathrm{~kW}$ per liter. The maximum fast and thermal neutron flux available to experimenters are $1 \times 10^{14}$ and $5 \times 10^{13}$ neutrons $/ \mathrm{cm}^{2}$-s, respectively. Experimental facilities available at the MITR include two medical irradiation rooms, beam ports, automatic transfer facilities (pneumatic tubes), and graphitereflector irradiation facilities. In addition, several in-core sample assemblies (ICSAs) are available. It generally operates 24/7, except for planned outages for maintenance. The MITR-II encompasses a number of inherent (i.e., passive) safety features including negative reactivity temperature coefficients of both the fuel and moderator; a negative void coefficient of reactivity; the location of the core within two concentric tanks; the use of anti-siphon valves to isolate the core from the effect of breaks in the coolant piping; a core-tank design that promotes natural circulation in the event of a loss-of-flow accident; and the presence of a full containment. These features make it an exceptionally safe facility.

The NRL has a long history of providing faculty and students with a high-quality neutron source complemented with an extensive infrastructure to facilitate its use. Its organizational structure is composed of four groups that work to sustain the NRL's long-standing record of safe operation, to continuously maintain and improve upon the state-of-the-art reactor and its experimental facilities, and to provide an environment of support and excellence for researchers and students. These groups are: Reactor Operations; Research, Development, and Utilization; Engineering; and Administration. The Laboratory's primary objective is in support of educational training and research in the areas of nuclear 


\section{ANNUAL REPORT FOR THE RESEARCH REACTOR INFRASTRUCTURE PROGRAM}

fission engineering, radiation effects in biology and medicine, material studies, neutron physics, geochemistry, and environmental studies. Through the years, MIT undergraduate and graduate students have benefited tremendously from the hands-on experience they have gained at the NRL. This is a result of students being able to conduct research that has resulted in their successful completion of more than two hundred MS and $\mathrm{PhD}$ theses or through the more than 300 students that have participated in the NRL's Reactor Operator Training Program. During this time period, cutting edge research has also been conducted by MIT faculty as well as faculty and scientists from other institutions. Current research and service areas supported and provided by MITR-II include:

Providing researchers with a service-based infrastructure that supports the US initiative for designing and building the next generation of nuclear reactors as a means of reducing the country's reliance on fossil fuels.

Supporting research in the area of advanced materials and fuel research.

Providing researchers with a service-based infrastructure that utilizes the MITR-II for trace element analysis, isotope production, and irradiation services.

The production of neutron transmutation doping of silicon.

Supporting an outreach program to the educational community to encourage understanding of nuclear energy and its applications.

Supporting MIT's educational missions by providing Independent Activities Period lectures; hosting Undergraduate Research Opportunities Program students; and offering lab courses for professionals, undergraduates, and advanced secondary school students.

Expanding the user base for underutilized experimental facilities

Support of web-enabled time-of-flight experimental facility.

Support of neutron scattering facility.

An exceptional feature of the MITR-II is its in-core loop capabilities. As a result, the NRL has a strong materials and in-core loop program that supports research in the areas of advanced materials and advanced fuels that are necessary for both existing and advanced power reactors. The MITR-II offers a unique technical capability that involves the design and use of in-core loops that replicate pressurized water reactor (PWR)/boiling water reactor (BWR) conditions to study the behavior of advanced materials and to perform scoping studies of advanced nuclear fuel. With rekindled national interest on the part of DOE and the nuclear industry in next-generation nuclear power systems, many using novel materials and advanced forms of fuels, facilities are needed to test material and fuel behavior in a variety of radiation environments. MITR is arguably the best-suited university reactor for carrying out such basic studies because of its relatively high-power density (similar to a light water reactor), the capability to control chemistry and thermal conditions to reflect prototypic conditions, its easy-access geometric configuration, and space for up to three independent irradiation tests.

A major goal of the MIT Research Reactor (MITR) is to maintain its partnership with the DOEIdaho National Laboratory's Advanced Test Reactor National Scientific User Facility (ATR-NSUF) which is charged with performing fuel and advanced materials irradiation experiments crucial to futuregeneration reactors. High temperature and radiation-resistant materials are needed for proposed designs that would exhibit high thermal efficiency as well as for hydrogen-production reactors. A related and equally important goal is to identify advanced fuels and materials that will enable both life-extension and improved economic performance of the existing LWR fleet. This collaboration, the first in an expected series of national partnerships designed to enhance the NSUF infrastructure and capabilities, is designed to increase user access to national reactor irradiations and testing capabilities. The NSUF test space at both reactors is made available at no cost to external users whose projects are selected via a peer review process. The MITR will offer a portion of its test capability to the NSUF experimenters. 
The NRL also seeks to support other key societal benefits of our reactor, such as the production of medical isotopes, with particular attention to the challenge posed by the extremely important Mo-99 isotope. This critical isotope is currently only produced in foreign reactors using HEU as the starting material. The MITR-II operating at $6 \mathrm{MW}$ will be a very useful facility for domestic production using molybdenum metal as the starting material, thereby eliminating the proliferation risk associated with international shipment of HEU. 


\section{ANNUAL REPORT FOR THE RESEARCH REACTOR INFRASTRUCTURE PROGRAM}

Page: B6 of B41

\section{Introduction}

\section{University of California - Davis}

The McClellan Nuclear Research Center (MNRC) is a facility built around a 2 MW TRIGA research reactor. The reactor became operational in 1990 making it the newest research reactor in the US. This facility was built by the US Air Force for the nondestructive inspection of aircraft structures for early warning signs of corrosion using neutron radiography. The University of California, Davis (UCD) took ownership of the reactor in 2000, following the closure of the McClellan Air Force Base. UCD has transformed the MNRC from an inspection facility for military aircraft into a center for university research. During this transformation tomography, neutron activation analysis, radiation effects testing, research scale isotope production, and silicon doping capabilities were established and developed. As such, the MNRC is one of the three largest university research reactors in the nation. The reactor is located adjacent to a large airstrip (of the former Air Force Base). The airstrip is beneficial in that relatively short half-life radioactive materials can be flown in and out of the facility quickly. The reactor is located only $40 \mathrm{~km}$ (25 miles) from the UC Davis campus providing researchers easy access to the facility.

\section{Facilities}

The MNRC has four bays to perform neutron imaging. Two bays are large enclosures that can accommodate large samples using robotic manipulators. The Center has the largest radiography capability in the US and can image samples as large as $10.00 \mathrm{~m}$ long, $3.65 \mathrm{~m}$ high, and weighing up to $2,270 \mathrm{~kg}$. The other two bays are laboratory-size rooms where smaller samples can be inspected using both radiography and tomography. The maximum usable neutron beam size is $22-50 \mathrm{~cm}$ in diameter with intensities of approximately $1 \times 105 \mathrm{n} / \mathrm{cm} 2 \cdot \mathrm{s}$ to $1 \times 107 \mathrm{n} / \mathrm{cm} 2 \cdot \mathrm{s}$, depending on the bay used. The highly collimated (L/D of 50 - 400) and thermalized neutron beams provide high spatial resolution and quality. Dynamic radiography can be taken at 30 frames/second; the film neutron radiography system can produce images with spatial resolutions of 50 micrometers; and MNRC's neutron tomography system has an overall spatial resolution of approximately 200 micrometers. The MNRC has multiple facilities to perform neutron irradiation. These include in-core areas, out-of-core areas and the four bays, accommodating a wide variety of sample shapes and sizes. These facilities enable the MNRC to also provide Neutron Activation Analysis (NAA), Radiation Hardness Testing, Isotope production and silicon doping.
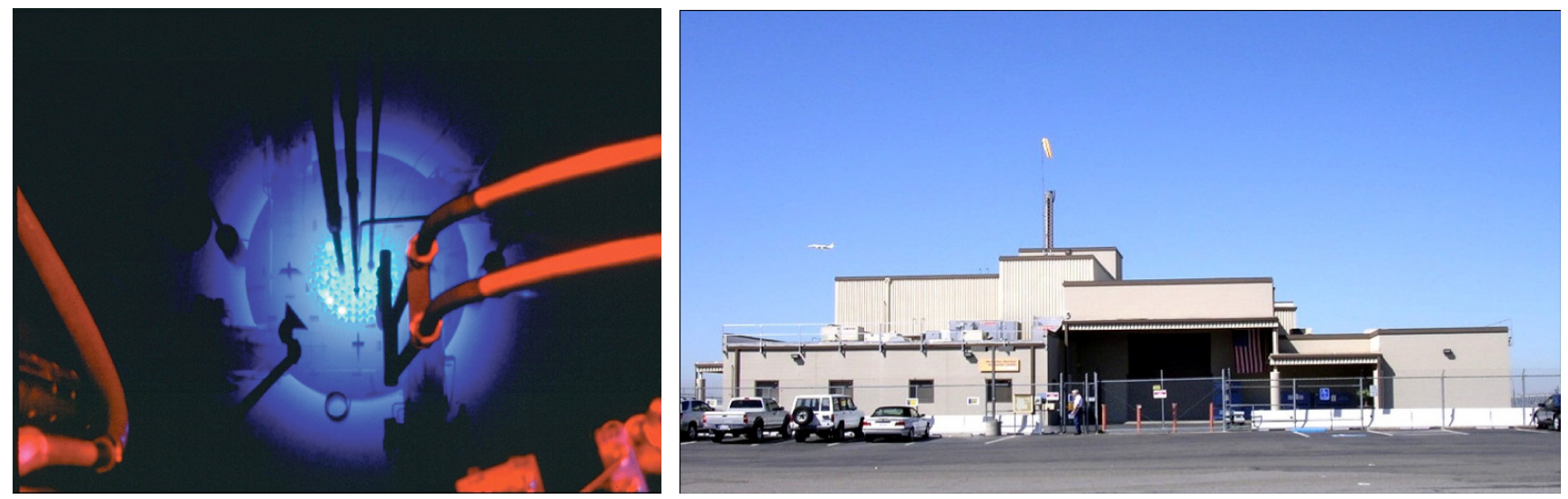

Figure 1: "blue glow" of the reactor and view of the MNRC building Project Institution 


\begin{tabular}{ll}
\multicolumn{1}{c}{ Project } & \multicolumn{1}{c}{ Institution } \\
\hline Tomography of Geological Minerals & UC Davis (Geology) \\
Fuel Cell Imaging & UC Davis (Mechanical Engineering) \\
CO2 Sequestration & UC Davis (Geology)/Los Alamos National \\
& Lab. \\
NAA of Biomass Fuels and Ashes & UC Davis (Geology) \\
Fast Neutron Damage of Magnets & UC Davis (Physics)/Stanford Linear \\
NAA of Organics (Cd detection) & Accelerator \\
Cu-64 Production & UC Davis (Chemistry) \\
Gd Concentration in Tissues & UC Davis (Biomedical Engineering) \\
Low-level Neutron Detector Calibration & UC Davis (Applied Science), UC Berkeley \\
Neutron Interrogation & Lawrence Livermore National Laboratory \\
Double b Decay & UC Berkeley (Nuclear Engineering) \\
Irradiation of Arabidopsis Seeds & Lawrence Berkeley National Laboratory \\
Neutron Imaging Detector Evaluation & UC Davis, Several international Universities \\
& Nova Systems, UC Davis School of \\
\hline
\end{tabular}

\section{Table 1: most recent research applications at MNRC}

\section{Current Applications}

Ongoing research applications are summarized in Table 1. Substantial work has been done on the tomography of geological materials. Neutron radiography is ideal for imaging the distribution of hydrated and organic phases within the minerals. Among the most recent efforts at MNRC is the imaging of fuel cell systems; NAA is used to detect low level Gadolinium contamination in human tissue; and Arabidopsis seeds are irradiated for mutagenesis. Numerous industrial applications are also done on a fee-for-service basis. Examples include radiography of precision cast parts (Boeing and Lockheed Martin), carbon build-up in jet engine fuel nozzles (Goodrich), and fire retardant tanks (US Forest Service). Numerous companies use the neutron beam to evaluate radiation effects on electronics (Cisco, Altera, Structural Integrity, Aerospace Corp., SAVEinc, and International Rectifier). In an agricultural application, NRT Growers are doing gamma irradiation of rice seeds.

\section{Planned projects}

The facility was originally built for neutron radiography, it is still among the leading neutron imaging facilities in the US. New detector techniques and new neutron optics are currently developed and tested worldwide. MNRC is in permanent contact with other facilities to keep its imaging facilities at the state of the art. This includes collaborations with National Laboratories such as Oak Ridge, Los Alamos and Lawrence Livermore as well as the NIST reactor. An effort to establish a high-pressure apparatus for neutron tomography is made in collaboration with Argonne and Los Alamos National Laboratories and the University of Edinburgh, Scotland. To better serve the NAA community upgrades of the detector systems are planned in collaborations with Lawrence Livermore and Lawrence Berkeley National Laboratories. These planned upgrades include detectors that are tailored to detect a particular isotope by using only a small energy range. To take full advantage of the reactors abilities to produce radioisotopes, a proposal has been submitted to become part of a consortium of university reactors to provide radiopharmaceuticals in response to a critical shortage in North America. 


\section{ANNUAL REPORT FOR THE RESEARCH REACTOR INFRASTRUCTURE PROGRAM}

\section{Rhode Island Nuclear Science Center}

The Rhode Island Nuclear Science Center is located on the Bay Campus of the University of Rhode Island. As enacted in the Rhode Island General Law, it was created for the purpose of research, experimentation, training personnel, testing of materials and techniques, and any other purposes that are deemed to be necessary for the health, welfare, and economy of the people of the state. By law, the use of the reactor is required to be made available to the colleges, universities, and industries of the state. Thus, rather than having one flagship university construct a reactor, the state of Rhode Island constructed a reactor for use by all of the colleges and universities within the state.

Facility History

In November 1958, the people of the state of RI approved a bond issue for the construction of the Rhode Island Nuclear Science Center (RINSC). In July 1962, the Atomic Energy Commission (AEC) issued a construction permit, and ground was broken in August that year. The AEC granted the initial facility license for operation up to $1 \mathrm{MW}$ in July 1964. At the end of that month the reactor was taken critical for the first time. In September 1968, the facility license was amended to allow operation up to 2 MW. In March 1993, an order was issued to convert the fuel from high enriched uranium (HEU), to low enriched uranium (LEU). In August that year, the fuel was converted and the initial LEU core was taken critical. In May 2004, a re-licensing application was submitted to the NRC. The facility is currently in the process of re-licensing.

Facility Mission and Vision

The mission of the facility is to serve as a tool for education, research, and service work related to the nuclear industry and technology. The long term vision for the facility is for it to become an integral part of the national infrastructure that educates future scientists and engineers about nuclear technology and the nuclear industry, is used for research that utilizes nuclear technology and helps test materials for the next generation of nuclear reactors, and provides technical expertise and technology for industrial purposes.

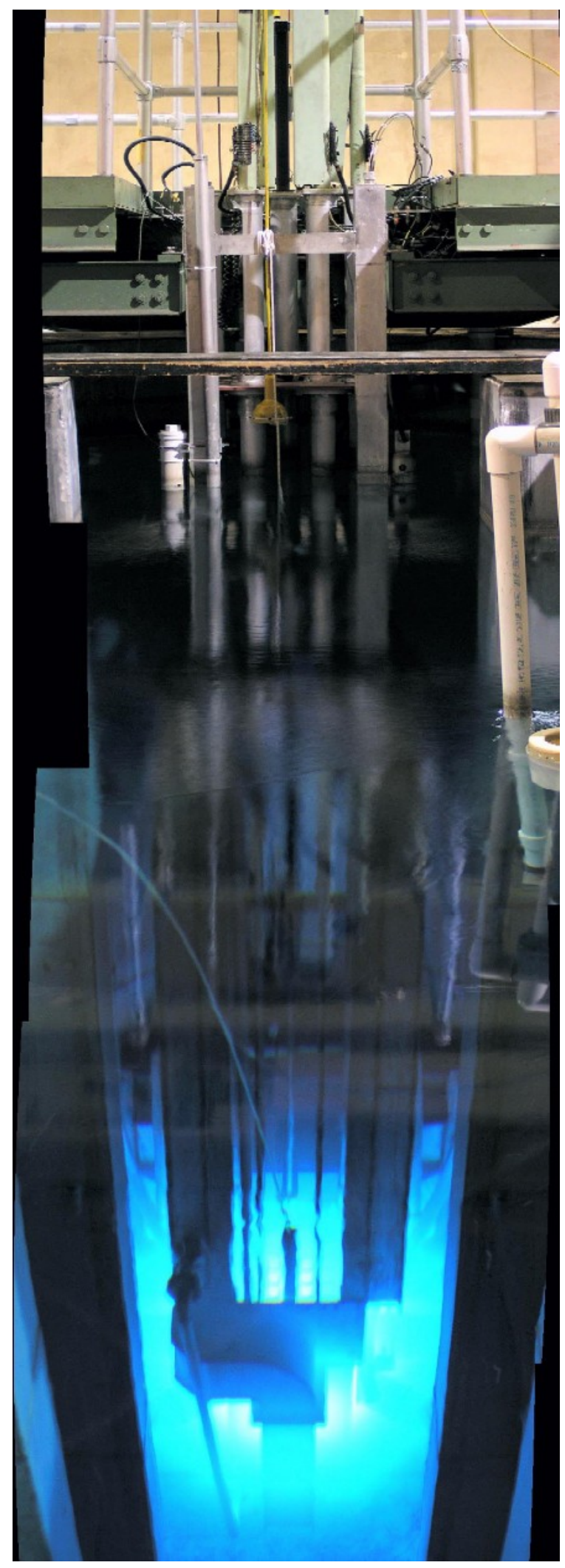




\section{Future Facility Upgrades}

The facility recently used federal grants and state funds to build a classroom and a student counting laboratory for use as part of the education mission. The counting laboratory is equipped with high purity GeLi detectors which allow students to learn about neutron activation analysis.

The facility also recently upgraded the control rod drive system to a digital system. It is currently in the process of converting the cooling system instrumentation and control to a digital system. The short term plan is to upgrade the facility IT system so that control rod position information, and cooling system parameters could be sent via the internet as real time information for use in university classrooms.

Funding has been received for the purpose of setting up an additional counting laboratory that will have a variety of different kinds of radiation detectors for use as part of a nuclear measurements course.

In the future, the facility will pursue a power upgrade to $5 \mathrm{MW}$ in order to make it more valuable as a tool for testing next generation nuclear reactor materials, and for producing medical isotopes.

\section{User Summary}

RINSC has a wide variety of educational users, from a wide variety of education levels. The facility routinely hosts tours for the general public, specific groups such as the Boy Scouts, middle schools, and high schools. The facility provides laboratory support for chemistry, physics, and nuclear engineering programs at the community college, undergraduate, and graduate levels of education from many of the local institutions of higher education.

Over the years, RINSC has engaged in numerous research projects involving atmospheric chemistry, archeology, neutron capture therapy, etc. More than one hundred graduate degrees have been granted to students that utilized the facility for their research projects.

RINSC has a couple of consistent industry users, including Bio Physics Assay Laboratory (BioPAL) and Infoscitex. BioPAL has pioneered the use of neutron activation analysis (NAA) to provide an alternative technique for in vivo cell tracking and quantifying studies. They make use of their technique for a variety of treatment and research purposes including the area of stem cell research. Their customers are world wide. Infoscitex is currently working on developing radiation resistant glass and glass adhesives for use in solar cells. Irradiated reactor fuel is used as a gamma radiation source for their tests.

Capabilities

RINSC has two rabbit systems, four incore facilities, a central irradiation facility, six beam ports, a through port, a thermal column, dry tubes, and an irradiator room.

The L2 beam port has a wide angle scattering diffractometer on it, and the R2 beam port has a small angle diffractometer on it. The small angle diffractometer uses a state of the art plane neutron detector that a RINSC staff member helped develop in collaboration with Oak Ridge National Laboratory. 


\section{Oregon State University}

The Oregon State University TRIGA Reactor (OSTR) is a flexible research tool which supports international research and teaching activities across multiple disciplines. The TRIGA Mark II reactor achieved initial criticality using 20\% enriched uranium fuel on March 10, 1967. Steady state power was limited to $250 \mathrm{KW}$, although reactor power could be briefly pulsed to several thousand MW. In 1969, maximum license steady state power was increased to $1 \mathrm{MW}$. In 1976, the OSTR was refueled with $70 \%$ enriched "FLIP" fuel. In 2008 the highly enriched fuel was replaced with $20 \%$ low enrichment fuel. The newest fuel maintains the performance characteristics of the FLIP fuel and has an expected lifetime of several decades.

The OSTR operates a suite of experimental facilities in support of teaching and research. During the July 2008 - June 2009 reporting period the reactor supported 61 different academic courses. The number of samples irradiated in the reactor during this period was 997. The Radiation Center provided service to 64 different organizations, $39 \%$ of which were from other states and $22 \%$ of which were from outside the U. S. and Canada. Users of the facility published or submitted 114 articles during this period. Teaching and research conducted at the OSTR spans fields such as chemistry, physics, geology, archaeology and of course nuclear engineering and radiation health physics. Experimental facilities can be operated simultaneously in support of multiple research projects. The OSTR experimental facilities include:

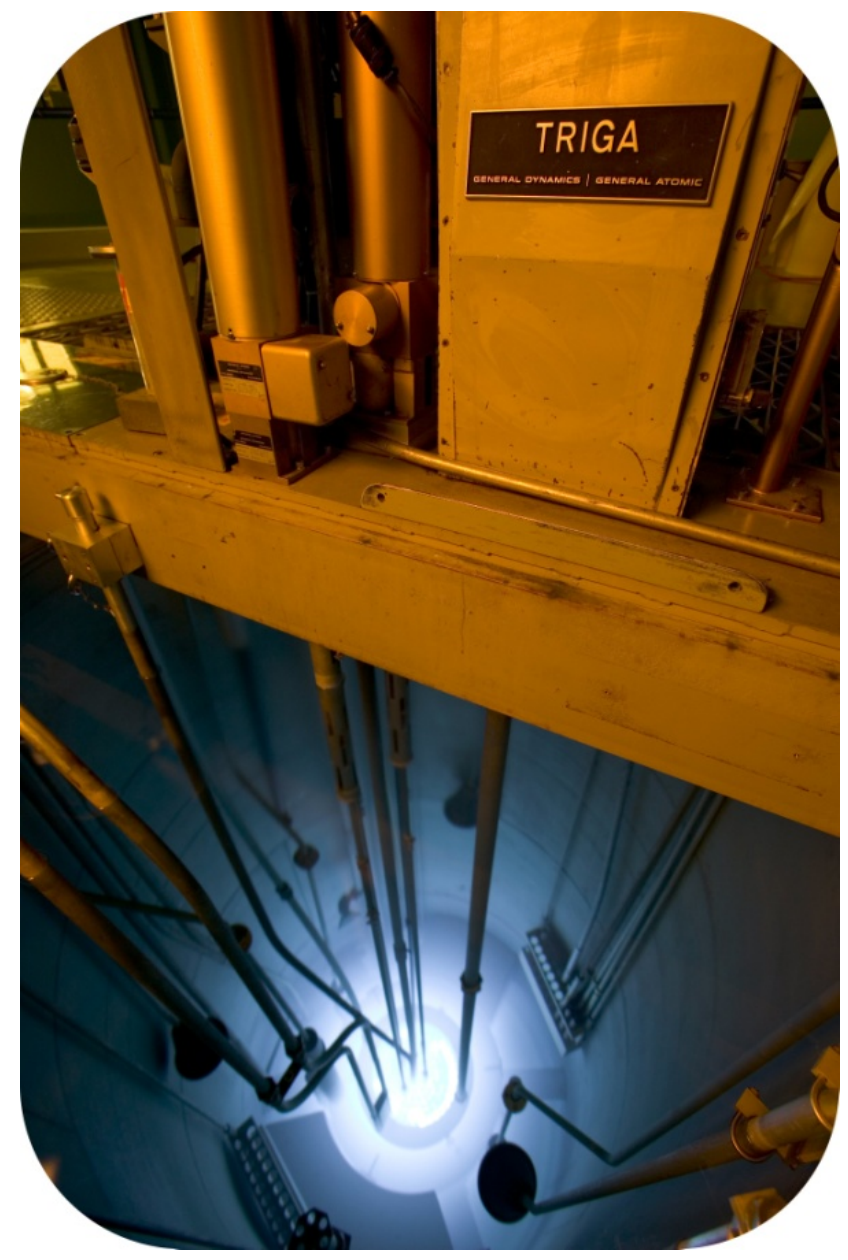

- $\quad$ G-Ring In Core Irradiation Tube (1E13 $\mathrm{n} / \mathrm{sec}^{\left.-\mathrm{cm}^{\wedge} 2\right)}$

- Pneumatic Rabbit (1E13 n/sec-cm²)

- Rotating Rack (1E12 n/sec-cm²)

- Thermal Column (8E10 n/sec-cm²)

- Neutron Radiography Facility (2E5 $\mathrm{n} / \mathrm{sec}^{\left.-\mathrm{cm}^{\wedge} 2\right)}$

- Prompt Gamma Neutron Activation Analysis / Neutron Depth Profiling Facility (1E7 n/sec-cm²)

- In Core Irradiation Tube (1E13 n/sec$\left.\mathrm{cm}^{\wedge} 2\right)$

- Cadmium Lined In Core Irradiation Tube (1E12 n/sec-cm^2) 
The staff of the OSTR looks forward to many years of productive operation. Plans include enhancement of existing facilities and addition of new facilities to allow neutron diffraction and crystallography studies. Upgrades of secondary cooling systems are in progress. Additional production of industrial and medical isotopes is also anticipated. 


\section{University of Texas at Austin}

The University of Texas at Austin has operated two different TRIGA reactors with the first located main campus beginning in 1969. The current TRIGA II reactor was licensed in 1993 for 1.1 MW operations, with pulsing to $2.2 \% \Delta \mathrm{k} / \mathrm{k}$, in the Nuclear Engineering Teaching laboratory (NETL) located on the Pickle research Center campus 8 miles north of main campus. The NETL TRIGA (the newest U.S. university reactor) is scheduled for license renewal in 2011, and will include a request for increased power level.

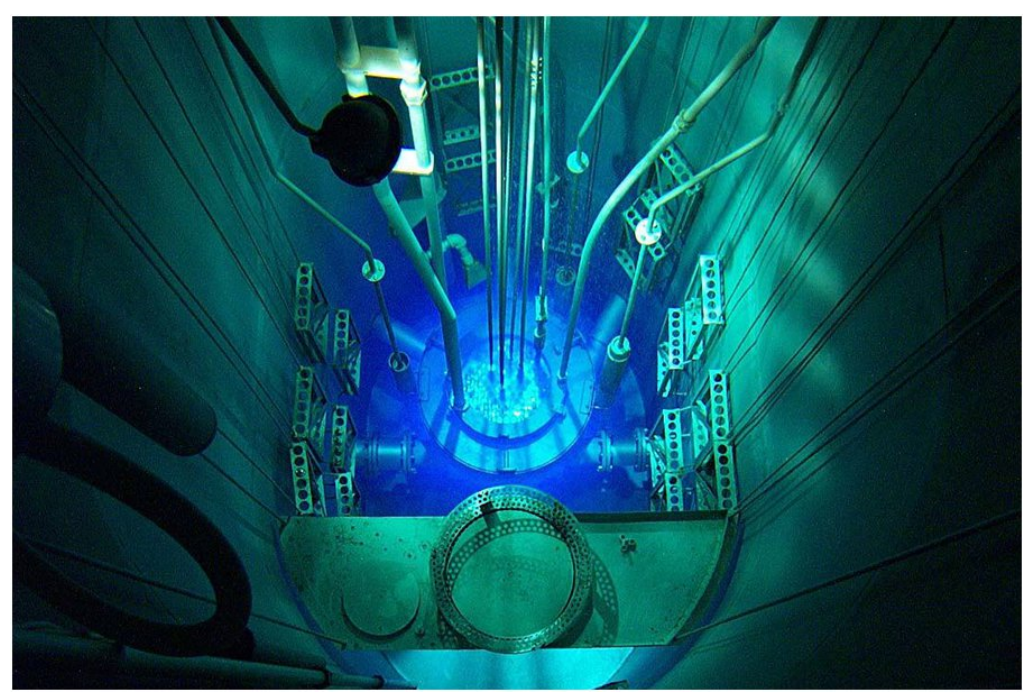

The NETL is a multifunction laboratory supporting education, research \& development, and nuclear-based testing. The reactor is a focal point for laboratory exercises and facility tours in the Nuclear and Radiation Engineering program of the Department of Mechanical Engineering. The reactor serves academic programs at other universities through the Big-12 Engineering Consortium, programs supporting historically black colleges and universities, and other special opportunities. The facility provides training and education for professional development programs with the USNRC and IAEA. The facility supports primary \& secondary education and various other organizational programs with tours and demonstrations. The facility supports research for undergraduate and graduate programs, other universities, industry, and government laboratories.

The NETL facilities include capabilities unusual or unique to most university reactors, including a cold source, 6-meter neutron guide tube, and a capillary focusing device

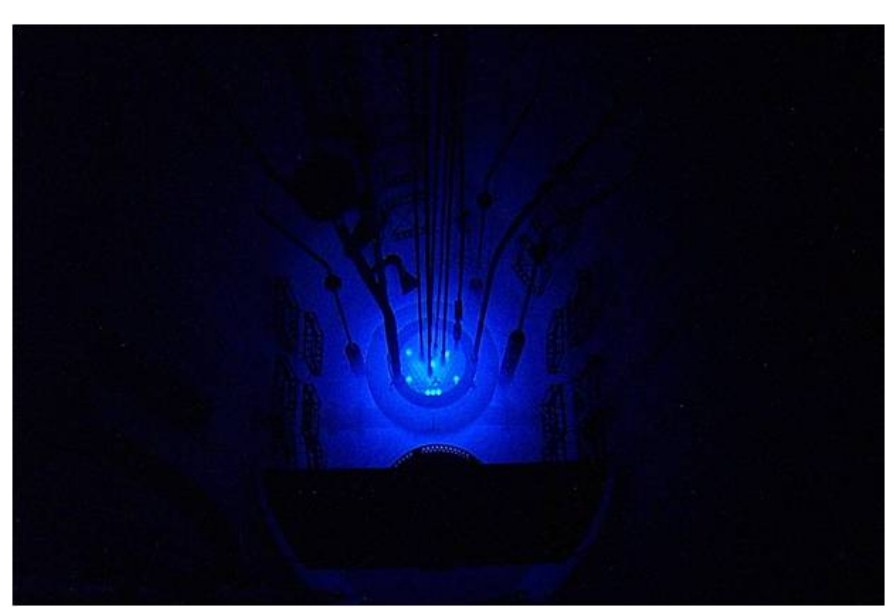

The University of Texas at Austin has operated two different TRIGA reactors with the first located main campus beginning in 1969. The current TRIGA II reactor was licensed in 1993 for 1.1 MW operations, with pulsing to $2.2 \% \Delta \mathrm{k} / \mathrm{k}$, in the Nuclear Engineering Teaching laboratory (NETL) located on the Pickle research Center campus 8 miles north of main campus. The NETL TRIGA (the newest U.S. university reactor) is scheduled for license renewal in 2011, and will include a request for increased power level. 


\section{ANNUAL REPORT FOR THE RESEARCH REACTOR INFRASTRUCTURE PROGRAM}

Page: B13 of B41

The NCSU PULSTAR is a $1 \mathrm{MW}$ pool type nuclear research reactor which is administered by the Nuclear Reactor Program and located in Burlington Laboratory on the N.C. State north campus. The NC State reactor is one of two PULSTAR reactors built, and the only one still in operation. The other reactor was a $2 \mathrm{MW}$ reactor at the University of Buffalo, which went critical in 1964 and was decommissioned in 1994.

The PULSTAR fuel is $4 \%$ enriched, pin type fuel consisting of uranium dioxide pellets in zircaloy cladding. This fuel gives the PULSTAR Reactor response characteristics that are very similar to commercial light water power reactors. These characteristics allow teaching experiments to measure moderator temperature and power reactivity coefficients including Doppler feedback.

The heavy fuel load in the PULSTAR, combined with a relatively high fuel-to-moderator ratio, results in high fast neutron leakage at the core boundary. This causes a large thermal neutron "reflector hump" at the core periphery yielding high thermal neutron fluxes at the sample irradiation facilities and beamports. (see

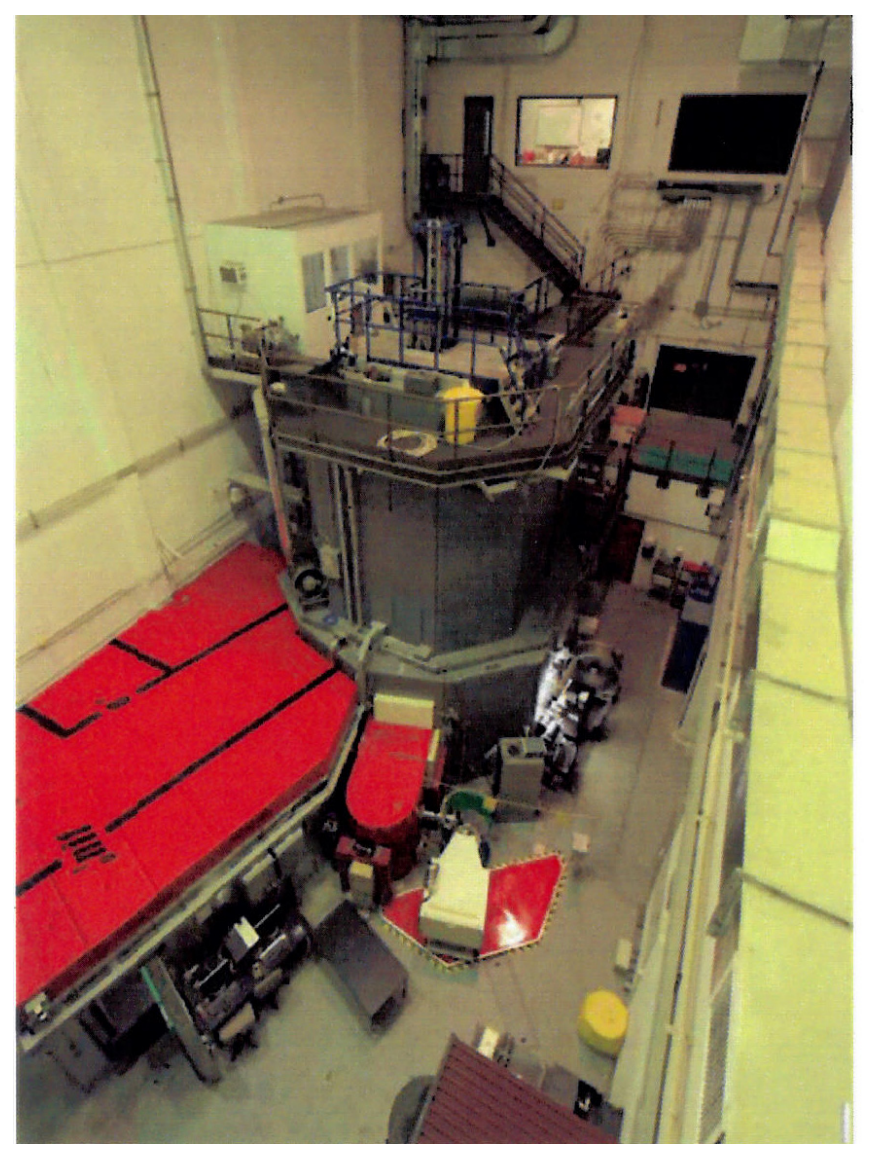
Table 1 below).

Currently the PULSTAR Reactor is undergoing a power upgrade to $2 \mathrm{MW}$.

\section{Internet Reactor Laboratories}

Internet Reactor Laboratories are available to external academic institutions who wish to utilize the PULSTAR in demonstrating nuclear reactor operations and kinetics for their students. This capability enriches academic programs at universities without research reactors of their own, and may be used to expand the educational opportunities for nuclear engineering students throughout the United States and internationally.

Distance learning laboratory participants are able to interact with PULSTAR reactor facility personnel through direct video and audio communication links, and have the ability to direct remote control cameras in the reactor control room. An online data acquisition system is utilized to provide real time visualization of the reactor operating parameters, and for collecting experimental data. 


\section{Experimental Facilities}

\begin{tabular}{|c|c|c|}
\hline \multicolumn{3}{|c|}{ Table 1: PULSTAR Irradiation and Beamport Experimental Facilities } \\
\hline Facility & Description & Intensity \\
\hline $\begin{array}{l}\text { Rotating Exposure } \\
\text { Ports } \\
4 \text { in-pool, ex-core }\end{array}$ & $\begin{array}{l}2.5 \% \text { ID wet sample } \\
\text { irradiation terminus }\end{array}$ & $\begin{array}{l}\text { 1.0x10 } 10^{15} \text { thermal } \mathrm{n} / \mathrm{cm}^{2} / \mathrm{sec} \\
1.0 \times 10^{12} \text { fast } \mathrm{n} / \mathrm{cm}^{2} / \mathrm{sec}^{2}\end{array}$ \\
\hline $\begin{array}{l}\text { Dry Exposure Ports } \\
2 \text { in-pool, ex-core }\end{array}$ & $\begin{array}{l}1.25 \% \text { ID dry sample } \\
\text { irradiation terminus }\end{array}$ & $\begin{array}{l}4.0 \times 10^{12} \text { thermal } \mathrm{n} / \mathrm{cm}^{2} / \mathrm{sec} \\
1.0 \times 10^{11} \text { fast } \mathrm{n} / \mathrm{cm}^{2} / \mathrm{sec}\end{array}$ \\
\hline $\begin{array}{l}\text { Pneumatic Terminus } \\
1 \text { in-pool, ex-core }\end{array}$ & $\begin{array}{l}1.25 \text { " ID fast rabbit sample } \\
\text { transfer system }\end{array}$ & $\begin{array}{l}1.0 \times 10^{15} \text { thermal n/cm } / \mathrm{cm}^{2} / \mathrm{sec} \\
1.0 \times 10^{12} \text { fast } \mathrm{n} / \mathrm{cm}^{2} / \mathrm{sec}\end{array}$ \\
\hline $\begin{array}{l}\text { Pool Standpipes } \\
4 \text { in-pool, ex-core }\end{array}$ & $\begin{array}{c}3.5 \% \text { ID dry sample } \\
\text { irradiation } \\
\text { positions }\end{array}$ & $\begin{array}{l}1.0 \times 10^{11} \text { thermal } \mathrm{n} / \mathrm{cm}^{2} / \mathrm{sec} \\
5.0 \times 10^{9} \text { fast } \mathrm{n} / \mathrm{cm}^{2} / \mathrm{sec}\end{array}$ \\
\hline Beamport \#1 & 6-in. diameter radial tube & $\begin{array}{l}1.0 \times 10^{12} \text { thermal } \mathbf{n} / \mathrm{cm}^{2} / \mathrm{sec} \text { at } \\
\text { core end }\end{array}$ \\
\hline Beamport \#2 & $\begin{array}{l}\text { 6-in. diameter tangential } \\
\text { 'through' tube }\end{array}$ & $\begin{array}{l}1.0 \times 10^{12} \text { thermal } \mathbf{n} / \mathrm{cm}^{2} / \mathrm{sec} \text { at } \\
\text { centerpoint }\end{array}$ \\
\hline Beamport \#3 & 8-in. diameter radial tube & $\begin{array}{c}1.0 \times 10^{12} \text { thermal } \mathbf{n} / \mathrm{cm}^{2} / \mathrm{sec} \text { at } \\
\text { core end }\end{array}$ \\
\hline $\begin{array}{l}\text { BP\#4: Neutron Powder } \\
\text { Diffraction Facility }\end{array}$ & 6-in. diameter radial tube & $\sim 0.5 \times 10^{5} 1.4 \AA \mathrm{n} / \mathrm{cm}^{2} / \mathrm{sec}$ on target \\
\hline $\begin{array}{c}\text { BP\#5: Neutron } \\
\text { Imaging } \\
\text { Facility }\end{array}$ & 6-in. diameter radial tube & $\begin{array}{c}\sim 5.0 \times 10^{\circ} \text { thermal } \mathrm{n} / \mathrm{cm}^{2} / \mathrm{sec} \text { at } 6.5 \\
\text { meter imaging plane }\end{array}$ \\
\hline $\begin{array}{l}\text { BP\#6: Intense Positron } \\
\text { Source Facility }\end{array}$ & 12 in. by 12 in. sq. radial & $\begin{array}{l}5-6 \times 10^{\circ} \text { positrons/second at } \\
\text { target; beam spot diameter is } 25 \\
\text { mm; e+ energy variable up to } 30 \\
\mathrm{keV}\end{array}$ \\
\hline $\begin{array}{l}\text { Thermal Column: } \\
\text { Ultra- } \\
\text { Cold Neutron Source } \\
\text { Facility }\end{array}$ & $\begin{array}{c}5^{\prime} \times 55^{\prime} \times 7^{\prime} \text { cavity in biologic } \\
\text { shield adjacent to reactor } \\
\text { core }\end{array}$ & $\begin{array}{l}\text { Projected intensity of } 6 \text { to } 16 \\
\text { million UCN's per second }\end{array}$ \\
\hline
\end{tabular}

The PULSTAR Reactor has four "User Facilities" which are available for use by research groups internal and external to the UNC system. Each of these four facilities harness the intense radiation fields emanating from the reactor beamports to create unique research and non-destructive diagnostic instruments.

\section{Neutron Powder Diffraction Facility}

The PNPD detector contains 15 neutron linear position sensitive proportional counters. The detectors have an active length of 24", a diameter of 1 " and are filled with 8 atm ${ }^{3} \mathrm{Helium}$ and $4 \mathrm{~atm}$ Argon. Neutron detection is through the reaction: $\mathrm{n}+{ }^{3} \mathrm{He} \rightarrow{ }^{1} \mathrm{H}+{ }^{3} \mathrm{H}+768 \mathrm{keV}$

The event position utilizes the charge division method. The neutron capture event injects charge on the detector anode which divides via the anode resistance resulting in signals from the preamplifiers connected to each end of the detector element. A simple model is sufficient to show the quotient of the preamplifiers signals yields the event position. The signals from the two preamplifiers connected to each detector element are processed by a custom microprocessor controlled dual-amplifier / dual-ADC circuit board that calculates and histograms the event positions and transfers these to the host computer on command. 


\section{Characteristics of NCSU Neutron Diffractometer Facility:}

- Variable resolution $\left(\mathrm{dd} / \mathrm{d}=1 \times 10^{-3}\right.$ or $\left.2 \times 10^{-3}\right)$

- $\quad$ Si bent perfect crystal focusing monochromator $1.478 \mathrm{~A}$

- $\quad 90^{\circ}$ take off angle, $5^{\circ}-125^{\circ}$ scattering range

- $\quad$ Detector to specimen distance: $1.6 \mathrm{~m}$ for high resolution, $1.15 \mathrm{~m}$ for high speed.

- Data acquisition 8 hours/pattern (high resolution), 2 hours/pattern (high speed).

- Large area position sensitive neutron detector array $15^{\prime \prime}$ x 24 ” spanning $20^{\circ}$ for high resolution or $30^{\circ}$ for high speed.

- $\quad$ Air-pad supported detector base.

\section{Diffractometer Applications}

Neutron diffraction data can be directly compared to theoretical models of crystal structure and composition. This opens a wide variety of possible applications:

- New material crystal structure and composition - In the development of new materials, the correlation of structure, synthesis conditions and properties is essential.

- Alloy atom location - The intensity of diffraction peaks is directly related to the atom species and fractional occupation of the crystal atom.

- Solid - Solid phase transformation - Many materials change their crystal structure in response to changes in their environment (temperature and pressure). New crystal phases result in new diffraction peaks - the unmistakable signature of phase transformation.

- Non-contact temperature measurement - The height of diffraction peaks is modulated by atomic thermal vibrations. Once calibrated, this can be an accurate means to measure temperatures when no other method is available.

- Chemical and solid-state reaction pathways and kinetics - Many chemical and solid-state reactions can be monitored quantitatively through the intensity of the diffraction peaks corresponding to the various components.

- Material stress - strain analysis - When crystalline materials are put under stress, the spacing between their atomic planes is changed. This results in a shift of the diffraction line positions. With neutron diffraction it is possible to probe material stress distributions in real engineering materials.

- Multiphase composition analysis - Many complex materials are mixtures - not alloys. Neutron diffraction measurements combined with Rietveld refinement can be used to analyze the composition and structure of the individual components.

\section{Neutron Imaging Facility}

The Neutron Imaging Facility is installed at beamports \#5 of the PULSTAR reactor, which provides a nominal source flux of $2.5 \times 10^{12} \mathrm{n} / \mathrm{cm}^{2} / \mathrm{sec}$ at $1 \mathrm{MW}$. The beam is collimated and filtered with 12 inches of single crystal sapphire.

The current aperture is a 1.44"x 1.75" (1.8" effective diameter) rectangular cross section opening in a BORAL plate, which yields an L/D ratio of $\sim 140$ at the 6.5 meter imaging plane. The resolution of the system is $\sim 33$ microns for conventional radiographic film. Measurements using ASTM standards show that the NIF achieves a beam quality classification of IA. 


\section{ANNUAL REPORT FOR THE RESEARCH REACTOR INFRASTRUCTURE PROGRAM}

The neutron imaging beam diverges to a 22 " diameter spot at the 6.5 meter imaging plane, allowing for uniform exposure of 14 " 17 " film cassettes. The imaging cave is fully accessible to personnel while the beam shutter is closed, allowing for the setup of experiments.

Imaging techniques available include conventional film, molecular phosphor digital imaging plates, and real-time Micro-Channel Plate and Thompson Tube imaging systems. Neutron tomographic measurement may be made utilizing a motorized sample positioning system in concert with real-time imaging systems.

\section{Film:}

- Up to 14" x 17" using Gadolinium converter screen and vacuum cassette.

- Maximum resolution $\sim 33$ microns.

- The typical film radiograph can be completed in $\sim 5$ minutes resulting in an average film density of 2.

- Gd2O3 images plates.

$$
\text { Molecular Phosphor Digital Image Plates; }
$$

- Maximum resolution $\sim \mathbf{1 0 0}$ microns.

- Linear dynamic range over 5 decades.

- Reusable.

- $15 \mathrm{~mm}$ diameter effective imaging area.

- Maximum Resolution $\sim \mathbf{3 0}$ microns.

- $\quad$ Maximum speed $=30$ frames per second (fps).

- Current CCD resolution $=2$ megapixels.

- 9 inch diameter effective imaging area.

- Maximum Resolution 200 microns.

- $\quad$ Maximum speed $=\mathbf{3 0}$ frames per second (fps).

- Parallel beam 3D tomography.

$$
\text { Tomography System: }
$$

- Horizontal and Vertical Translation controlled by stepper motor and a Servo Feedback Rotary Stage.

- MCP and Thomson Tube detector system.

- $\quad$ Time for 180 views with 512 frame averaged $\sim 2$ hour and $30 \mathrm{~min}$.

- Resolution depends on number of views taken.

- Reconstruction using Filtered Back Projection and Statistical Techniques.

\section{Intense Positron Source}

At the NC State University PULSTAR Reactor laboratory, an intense positron source has been developed to supply a high rate positron beam to two different positron/positonium lifetime spectrometers. The positron source is comprised of a Tungsten moderator assembly surrounded by a Cadmium shroud located adjacent to the PULSTAR core in beamport \#6. Positrons are created when gamma rays emanating from the reactor, and from neutron capture in the Cadmium shroud, interact via pair

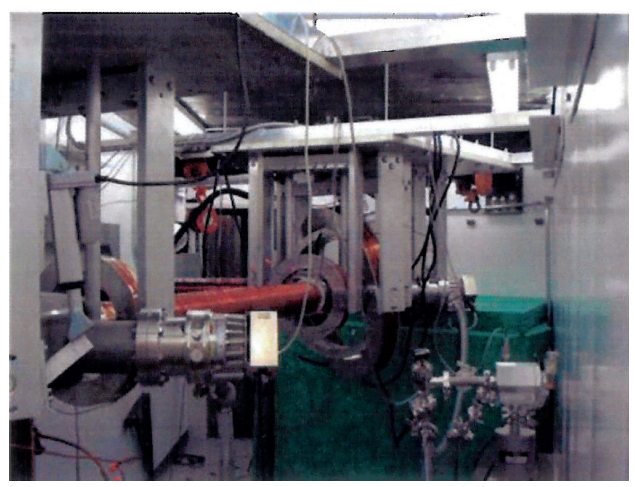
production with the Tungsten. 


\section{ANNUAL REPORT FOR THE RESEARCH REACTOR INFRASTRUCTURE PROGRAM}

Two positron spectrometer instrument stations are under development:

- Ps_PALS: Positronium Annihilation Lifetime Spectrometer

The Ps-PALS spectrometer is dedicated to the measurement of lifetimes in materials where positronium formulation is promoted. The beam is extracted from the magnetic field and undergoes two stages of brightness enhancement before being focused onto the sample where a secondary electron timing technique is implemented. The timing resolution of this spectrometer is designed to be $\sim 0.5$ nanosecond. This spectrometer is expected to provide a 1-2 mm diameter beam spot on target at beam energies up to $30 \mathrm{keV}$ in a zero magnetic field.

- E+ PALS: Positron Annihilation Lifetime Spectrometer

The $\mathrm{e}^{+}$-PALS spectrometer is dedicated to measuring positron lifetimes on the order observed in materials such as metals and semiconductors (i.e., lifetimes in the range of 300 picoseconds or less). The instrument utilizes time varying electric fields to generate narrow bunches $(<300 \mathrm{ps})$ of positrons with a $50 \mathrm{MHz}$ rep. rate and the beam is magnetically guided to the sample, which can be biased to negative potentials to vary the implantation energy. Positrons entering the spectrometer are first implanted into a $1 \mathrm{~cm}$ diameter, $100 \mathrm{~nm}$ thick single crystal tungsten remoderator foil to which a $50 \mathrm{MHz}$ ramp voltage is applied. This acts as a pre-buncher for the main bunching stage. The velocity modulation is optimized by changing a DC offset placed on the moderator ensuring that the focal point of the pre-buncher is at the entrance of the main buncher. This is a double gap device comprising a $9 \mathrm{~cm}$ long tube with a $50 \mathrm{MHz}, 280 \mathrm{~V}$ sine wave applied, to achieve time focusing at the sample. The length of the bunching electrode is calculated so that positrons entering the buncher exit if phase with the applied sine wave, the amplitude of which is chosen to result in optimum time focusing at the sample.

\section{Ultra-cold Neutron Source}

The total neutron flux inside deuterium is expected to be about $5 \times 10^{11} \mathrm{n} / \mathrm{sec} / \mathrm{cm}^{2}$. From this amount we expect to convert $10^{4}$ of them per second into the UCN energy range, and $30 \%$ of them should make it to the position of experiments, which is indeed quite efficient: our 3-step moderation will provide a useful density at least $30 \mathrm{UCN} / \mathrm{cc}$ per $1 \mathrm{MW}$ of reactor power as compared with about 1 $\mathrm{UCN} / \mathrm{cc}$ per $1 \mathrm{MW}$ at the existing UCN facility at ILL, France.

\section{Status/Development Timeline}

- Cryogenic testing of the source cryostat assembly outside the

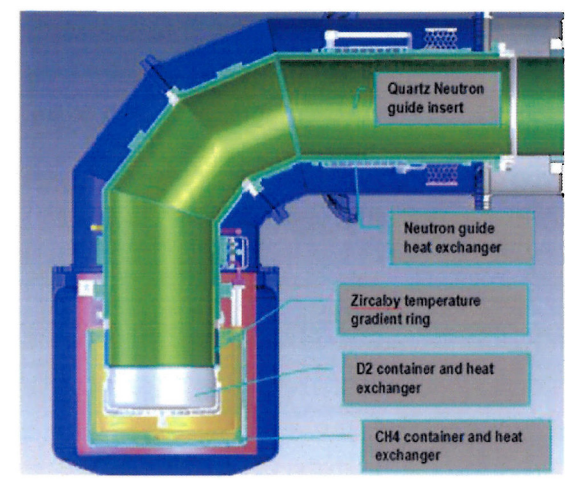
biological shield - in progress as of August 2010.

- Commissioning of the liquid helium circulation system through the cryostat.

- Commissioning of the methane gas handling system and optimization of procedure for solid deuterium growth.

- Commissioning of the deuterium gas handling system and optimization of procedure for solid deuterium growth.

- Commissioning of the entire system installed at the operational location inside the biological shield of the PULSTAR reactor.

\section{Nuclear Services}

The mission of Nuclear Services is to provide high quality analytical and irradiation services utilizing the irradiation and user facilities associated with the PULSTAR Reactor. 
These services are available for use by research faculty and staff within the UNC system or at other academic institutions, and by governmental agencies and industries in the State of North Carolina and the Nation.

Primary services offered include:

- Neutron Activation Analysis

- Neutron Radiography

- Reactor Irradiation \& Isotope Production

\section{Neutron Activation Analysis}

Samples analyzed via INAA at NC State typically fall into one of the four general categories listed below:

Agricultural, Biological, and Environmental Samples: Agricultural products, benthic organisms, biological tissues \& fluids (blood, hair, nails, organs, urine), bone, fertilizer, fish (tissue and eggs), food products, forensic samples, plants, sediment, sludges, vegetation, water, wood.

Industrial Samples: Crude oil, filter media \& resins, fly ash, plastics, synthetic fibers, textiles.

High Purity Matrix Samples: Carbon/graphite, ceramics, chemicals, metallic alloys,

pharmaceuticals, refractory kiln bricks, semiconductor substrates and processing materials.

Geologic Samples: Coal, ores, rocks, soils/sediments.

\section{Reactor Irradiations \& Isotope Production}

Large diameter "Standpipes" may be located in the reactor pool directly adjacent to the reactor. These facilities may be utilized for irradiating experimental packages and for isotope production. Examples of experimental packages include:

- Nuclear instruments and detectors (e.g. for calibration measurements or radiation damage studies).

- Semiconductor devices and materials (e.g. for radiation damage studies or transmutation doping).

- Fiber optic sensors.

- Nuclear materials (e.g. fueled experiments, vessel steel)

- Fission Track etch samples (e.g. geologic/ore samples)

Examples of isotopes that may be produced include:

- Antimony-122/124

- Argon-41

- Bromine-82

- Cobalt-60

- Iron-59

- Sodium-24

- ....and many others depending on user's requirements. 


\section{ANNUAL REPORT FOR THE RESEARCH \\ REACTOR INFRASTRUCTURE PROGRAM}

Page: B19 of B41

\section{Penn State University \\ Penn State Breazeale Reactor (PSBR)}

Location: Pennsylvania State University

Currently Supporting: Multiple Programs including Nuclear Engineering Program research and courses

Remarks: 1-MW TRIGA, Mark III Reactor (PSBR). Second License renewal application was submitted in 2005 and approved by US NRC in 2009. Various upgrades of experimental facilities including new radiochemistry and nuclear security education program are in progress.

The Radiation Science and Engineering Center (RSEC) facilities include the Penn State Breazeale Reactor (PSBR), gamma irradiation facilities (In-pool Irradiator, Dry Irradiator, and Hot Cells), and various radiation detection and measurement laboratories. The PSBR, which first went critical in 1955, is the nation's longest continuously operating university research reactor. The PSBR is a $1 \mathrm{MW}$, TRIGA with moveable core in a large pool and with pulsing capabilities. The core is located in a $24 \mathrm{ft}$ deep pool with $\sim 71,000$ gallons of demineralized water.

A picture of the reactor core is shown above. A variety of dry tubes and

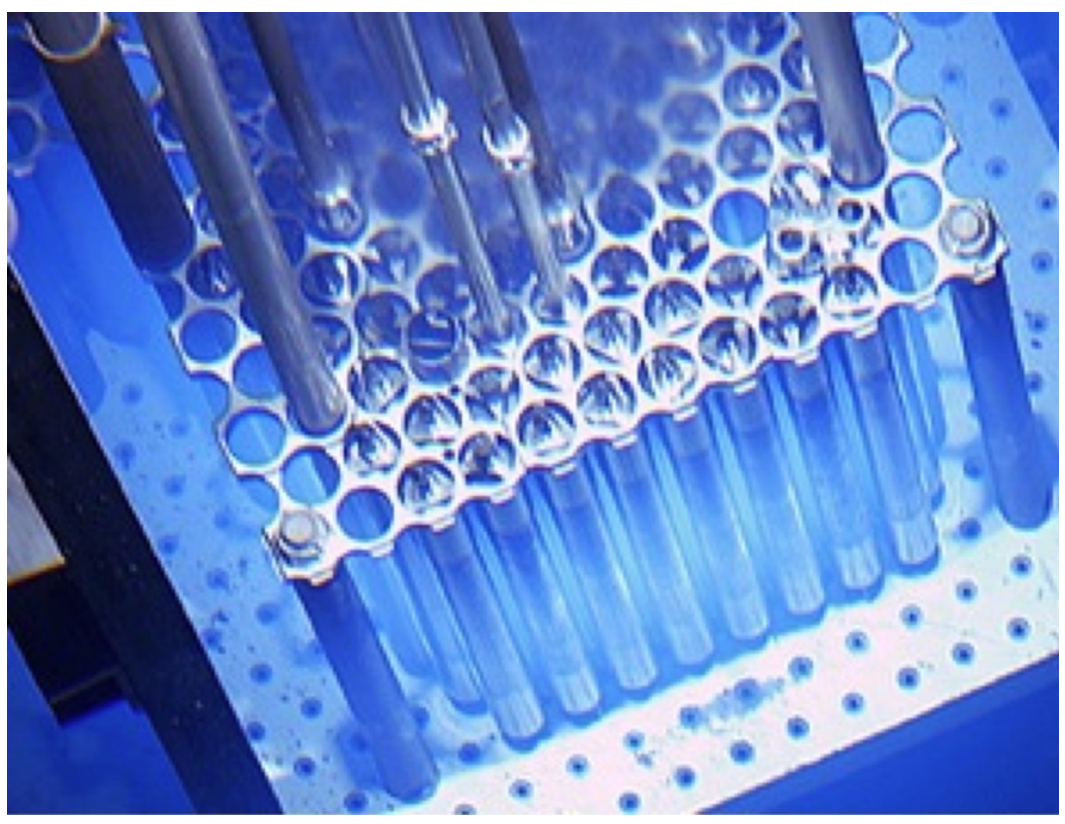
fixtures are available in or near core irradiations for Neutron Activation Analysis and other applications. A pneumatic transfer system is also available for irradiation of samples for Neutron Activation Analysis. When the reactor core is placed next to a $\mathrm{D}_{2} \mathrm{O}$ tank and graphite reflector assembly near the beam port locations, thermal neutron beams become available for neutron transmission and neutron radiography measurement from two of the seven existing beam ports. In steady-state operation at $1 \mathrm{MW}$, the thermal neutron flux is $1 \times 10^{13} \mathrm{n} / \mathrm{cm}^{2} \mathrm{sec}$ at the edge of the core and $3 \times 10^{13} \mathrm{n} / \mathrm{cm}^{2} \mathrm{sec}$ at the central thimble. The PSBR can also pulse with the peak flux for maximum pulse $\sim 6 \times 10^{16} \mathrm{n} / \mathrm{cm}^{2} \mathrm{sec}$ with pulse half width of $\sim 10 \mathrm{msec}$.

The improvements for some existing RSEC facilities are currently underway or just completed. New core-moderator and beam port arrangement are planned with an expansion of the existing beam laboratory. The research areas envisioned for RSEC's new beam port/beam hall design primarily will be in cutting-edge nuclear science and materials science. Examples include the following: a Neutron Depth Profiling facility for depth vs. concentration measurements in materials; a Neutron Imaging facility that includes a neutron computed tomography capabilities for imaging of fuel cells and other technologically important components; a Cold Neutron Source and Cold Neutron Prompt Gamma Activation Analysis for neutron focusing research and determination of impurities in historically or technologically important material; and a Neutron Powder Diffractometer for structural determination of materials. 


\section{Texas A\&M University}

The Texas A\&M University Nuclear Science Center (NSC) is a multi-disciplinary research and education center supporting basic and applied research in nuclear related fields of science and technology as well as providing educational opportunities for students in these fields as a service to the Texas A\&M University System and the state of Texas.

The NSC reactor, an 1-MW pool-type TRIGA reactor, is at the heart of the NSC facilities which includes a 2-MW micro-beam accelerator, a ${ }^{60} \mathrm{Co}$ gamma calibration range, a real-time neutron

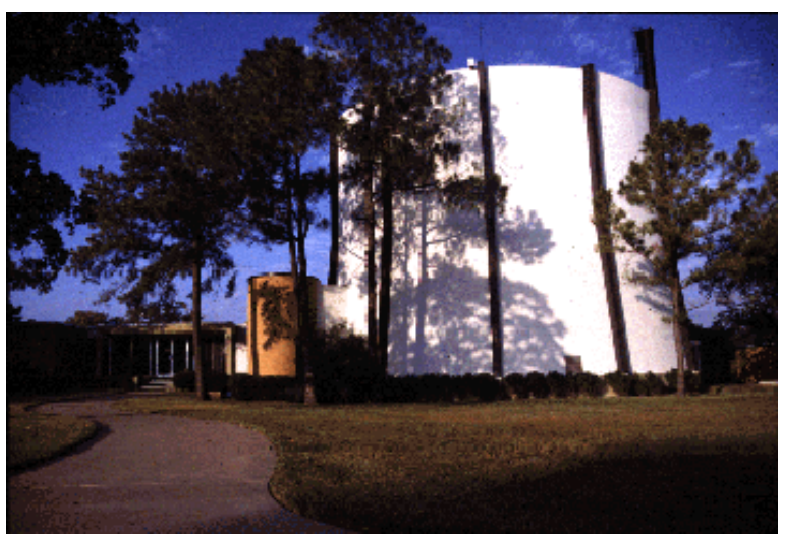
radiography facility, hot cells and manipulators, radiation measurement laboratories, radiochemical laboratories, many HPGe gamma spectroscopy systems, and a variety of instruments for radiation detection and measurement.

The NSC reactor is designed for easy load and unload of various types of samples and is being actively used to produce various kinds of radioisotopes for industry, hospitals, and academic users. The NSC is also nationally recognized for its neutron activation analysis (NAA) services to many research and academic institutions in the western part of the United States. The NSC reactor actively supports the Nuclear Engineering Department on campus, one of the largest nuclear engineering programs in the United States. The NSC reactor is serving approximately 50 nuclear engineering students annually through its teaching and research activities. The NSC reactor has been also successfully used to attract students to nuclear engineering programs by providing introductory tours and part-time jobs. The NSC reactor has become one of the major attractions on campus. Through offering tours, the NSC is emphasizing the importance of nuclear energy in the United States.

With the strong support from the University, the NSC is continuously increasing the diversity of its facilities and services. 


\section{ANNUAL REPORT FOR THE RESEARCH REACTOR INFRASTRUCTURE PROGRAM}

\section{University of Massachusetts at Lowell}

The University of Massachusetts-Lowell Research Reactor (UMLRR) is an LEU f ueled, one-megawatt, steadystate, pool-type reactor. It is one of three facilities within the University of Massachusetts-Lowell Radiation Laboratory, which includes various Co-60 gamma irradiators and a 5.5 MV Van de Graff accelerator. The principal purpose of the UMLRR is to provide a multidisciplinary facility for use in nuclearrelated education and research.

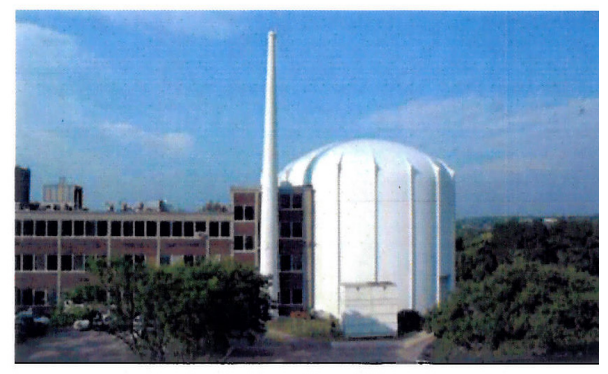

\section{Reactor Facilities}

Various experimental facilities within the UMLRR produce thermal neutrons for radioactivation purposes and fast (fission spectrum) neutrons for radiation effects research. Reactor facilities include the following:

- $\quad 3$ horizontal beam ports (one 8-inch and two 6-inch)

- 1 pneumatic sample transfer tube

- $\quad$ multiple in-core radiation baskets

- a graphite thermal column

- a large ex-core fast neutron irradiation facility

- $\quad$ digital neutron radiography facility

- Nitrogen-16 production facility

- $\quad$ Control room with digital acquisition and control,

and web-based data monitoring and retrieval

The reactor license also provides for a substantial Co-60 inventory. A number of high dose and low dose gamma irradiation facilities have been established to meet the needs of the aerospace and nuclear industries. The gamma facilities have a quality assurance program meeting 10CFR 50 Appendix-B requirements. The fast neutron and gamma facilities have been included in a lab suitability determination by the Defense Logistics Agency.

\section{Education and Research Uses}

The major uses of the reactor include instrumental neutron activation analysis, neutron

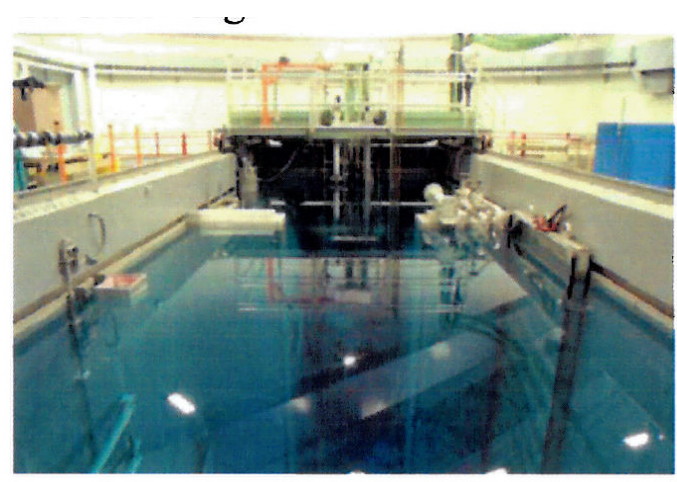
radiography, neutron and gamma irradiation of biological media, neutron irradiation of borated polymers, the production of short-lived isotopes for educational and research purposes, educational coursework, and personnel training. UMass Lowell was selected as part of a $\$ 1.5 \mathrm{M}$ consortium awarded by the Department of Energy to study the scattering properties of neutrons. Part of the research work is expected to use the research reactor as a neutron source for various experiments. Over 30 organized groups are typically provided tours of the facilities each year.

\section{Future Applications}

The UMLRR is one of only three URRs in the US that has a full containment building. Despite the current license level of $1 \mathrm{MW}$, the facility is designed for power levels up to 5MW. The current license is to be renewed in 2015. With adequate funding for cooling system improvements and a comprehensive 
safety analysis, the UMLRR could be licensed up to 5MW, which would provide substantially higher neutron fluences and subsequent research capabilities. 


\section{ANNUAL REPORT FOR THE RESEARCH REACTOR INFRASTRUCTURE PROGRAM}

\section{University of Wisconsin}

The University of Wisconsin Nuclear Reactor is a $1 \mathrm{MW}$, open pool-type reactor, fueled with TRIGA-LEU fuel with pulsing capabilities. The reactor first went critical in 1961 as a 10kW reactor utilizing GE-MTR fuel. It underwent a power up rate to $250 \mathrm{~kW}$ in 1964 until 1967 at which time it was refueled with GA-TRIGA standard $8.5 \mathrm{w} / \mathrm{o}, 20 \%$ enriched fuel and increased power to $1 \mathrm{MW}$. From 1973 to 1979 the facility commence a refueling to an all TRIGA-FLIP core $(8.5 \mathrm{w} / \mathrm{o}, 70 \%$ enriched HEU). It operated with the all HEU core until 2009 at which time a complete refueling to TRIGA $30 \mathrm{w} / \mathrm{o}, 20 \%$ enriched LEU fuel was initiated.

The UW Nuclear Reactor serves a vital role in the nuclear engineering curriculum and supporting research within the UW College of Engineering as well as other UW departments and other universities throughout the country. The UW Nuclear Reactor is an integral part of the nuclear engineering program; several core nuclear engineering courses directly use the reactor. The facility also provides significant educational outreach to the local community through the use of internet based remote
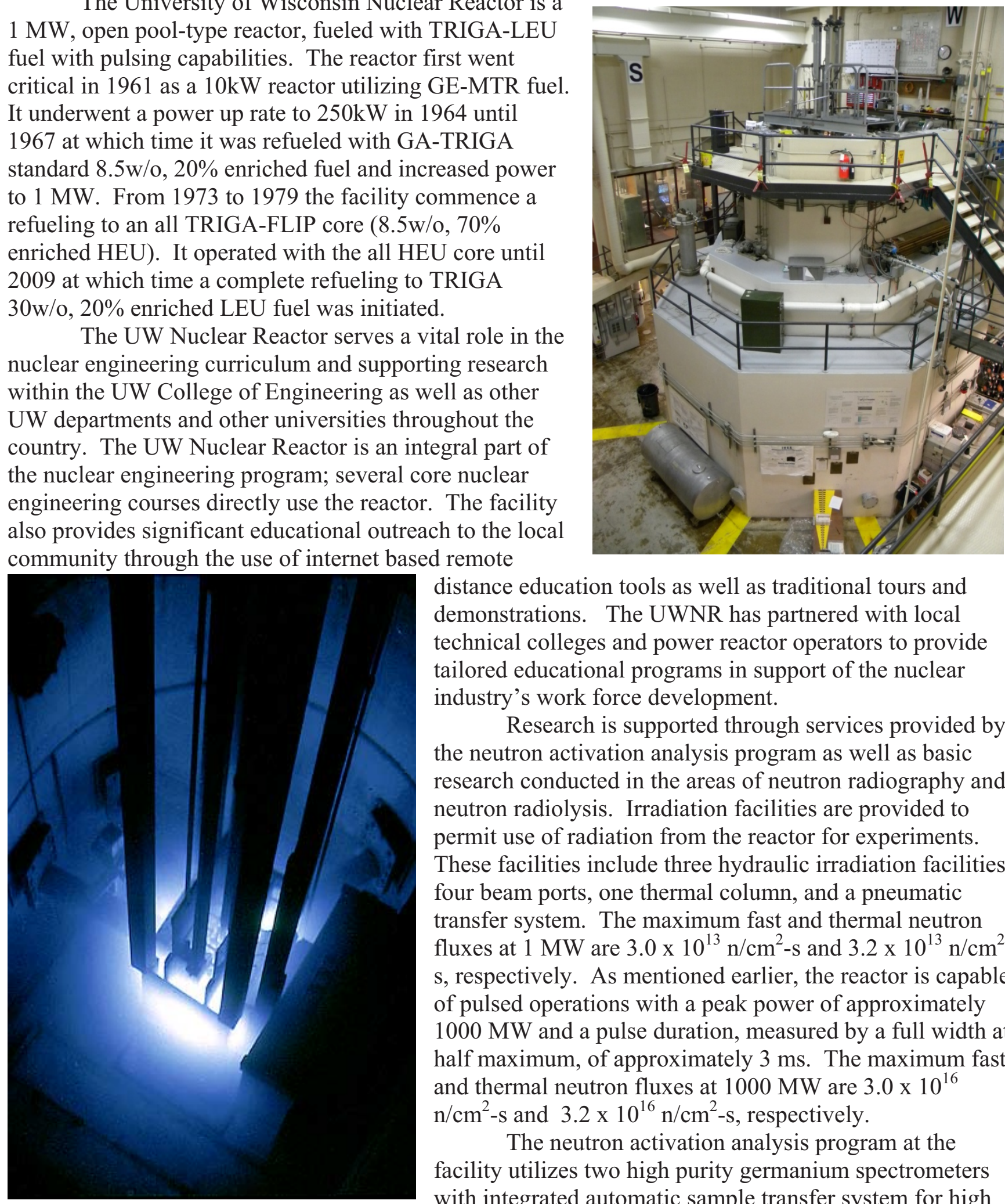

distance education tools as well as traditional tours and demonstrations. The UWNR has partnered with local technical colleges and power reactor operators to provide tailored educational programs in support of the nuclear industry's work force development.

Research is supported through services provided by the neutron activation analysis program as well as basic research conducted in the areas of neutron radiography and neutron radiolysis. Irradiation facilities are provided to permit use of radiation from the reactor for experiments. These facilities include three hydraulic irradiation facilities, four beam ports, one thermal column, and a pneumatic transfer system. The maximum fast and thermal neutron fluxes at $1 \mathrm{MW}$ are $3.0 \times 10^{13} \mathrm{n} / \mathrm{cm}^{2}$-s and $3.2 \times 10^{13} \mathrm{n} / \mathrm{cm}^{2}$ $\mathrm{s}$, respectively. As mentioned earlier, the reactor is capable of pulsed operations with a peak power of approximately $1000 \mathrm{MW}$ and a pulse duration, measured by a full width at half maximum, of approximately $3 \mathrm{~ms}$. The maximum fast and thermal neutron fluxes at $1000 \mathrm{MW}$ are $3.0 \times 10^{16}$ $\mathrm{n} / \mathrm{cm}^{2}$-s and $3.2 \times 10^{16} \mathrm{n} / \mathrm{cm}^{2}$-s, respectively.

The neutron activation analysis program at the facility utilizes two high purity germanium spectrometers with integrated automatic sample transfer system for high 
throughput, rapid, irradiation and analysis. This capability is being enhanced with the development of a complementary prompt gamma neutron activation analysis system.

Future enhancements to the facility will be directed towards materials studies including development of new capabilities such as neutron depth profiling and neutron diffraction as well as enhancement of existing facilities such as refurbishment of the facility's hot cell and the current neutron imaging facility. 


\section{ANNUAL REPORT FOR THE RESEARCH REACTOR INFRASTRUCTURE PROGRAM}

\section{Washington State University}

\section{The WSU Nuclear Radiation Center}

(WSUNRC) is an independent unit within the Office of Research at Washington State University. The WSUNRC operates as a campus-wide research facility, and provides research support, irradiation services, radioisotope production and laboratory space to faculty and students throughout the university. The WSUNRC operates the WSU nuclear reactor, which is a $1000 \mathrm{~kW}$ open-pool TRIGA-fueled reactor. Criticality was first reached in March, 1961 as a General Electric design using MTR-fuel, with a licensed power level of $100 \mathrm{~kW}$. The reactor was converted to use TRIGA fuel in 1967, with an accompanying license

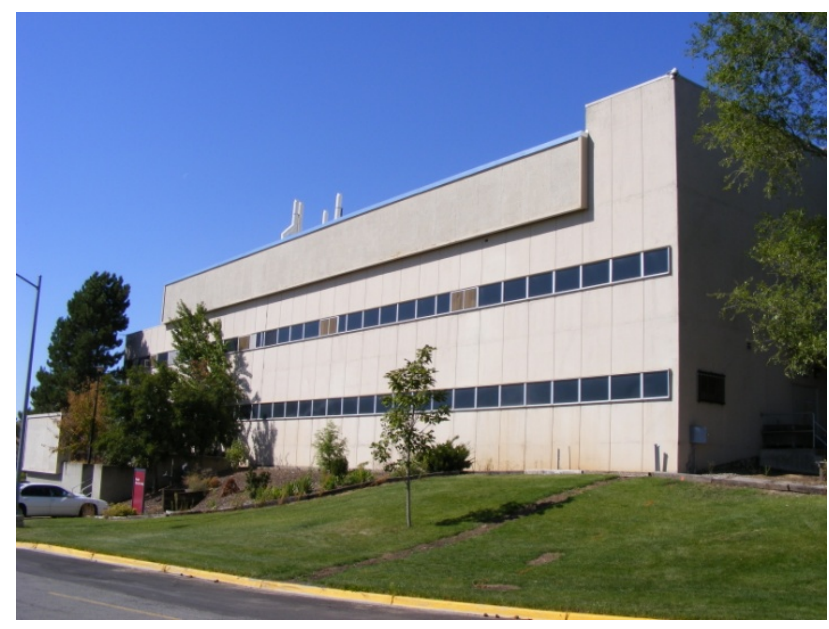
modification allowing operation up to $1000 \mathrm{~kW}$. The reactor was fueled with 8.5 weight percent, $20 \%$ enriched standard TRIGA fuel until 1976, at which time it was converted to operate with HEU fuel provided though the Fuel Life Improvement Program (FLIP). The WSU reactor was operated with a mixture of standard 8.5/20 and FLIP HEU-fuels until 2008, when the reactor was converted to an entirely LEU fueled core.

Washington State University maintains close ties with the Pacific Northwest National Laboratory (PNNL). The WSUNRC performs irradiation services, radioisotope production and analytical services on a frequent basis for researchers at PNNL. The WSU reactor is also used to produce radionuclides for research use in the radiochemistry program at WSU. The proximity to a source of radioactive materials and specialized radiochemistry laboratory space provides WSU faculty and students an unusual opportunity to carry out research that is not possible at most other educational institutions. Neutron activation analysis is carried out at the WSUNRC as a research and analytical service that is provided to graduate students and faculty members at the university. There are 14 irradiation positions adjacent to the reactor core, including a cadmium lined irradiation position that is used to provide epithermal and fast neutron irradiation. The WSUNRC also features a full suite of nuclear analytical equipment such as liquid scintillation counting, automatic gamma counting, alpha-spectroscopy and eight high purity germanium gamma spectrometers. The WSUNRC has recently received a grant to purchase a single

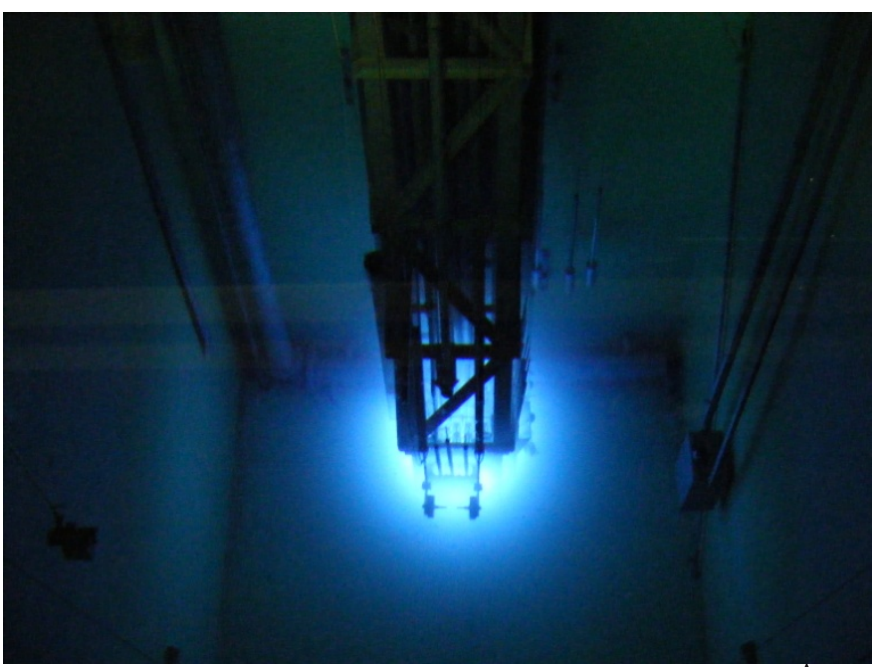
crystal x-ray diffractometer, which will be used for investigation of solid-state structure of radioactive materials, including molecules that incorporate radioisotopes that will be produced in the WSU reactor.

WSU does not have a nuclear engineering major, but does offer courses in nuclear engineering for undergraduate and graduate students through the College of Engineering. A course in Nuclear Reactor Operations is offered by the WSUNRC through the WSU Department of Chemistry. The course is designed to give students a basic understanding of the principles of nuclear reactor operation and provides a foundation for 
continued study to prepare students to take the U.S. Nuclear Regulatory Commission (NRC) Reactor Operator licensing examination.

The WSUNRC produces radioisotopes for national laboratory and business clients who use the materials for research and commercial purposes. The income that is generated through radionuclide production and irradiation services is reinvested by supporting students and staff members who provide these services in addition to supporting R\&D by staff and students. The WSU reactor has pulsing capability, with pulses reaching as much as $1000 \mathrm{MW}$. The pulsing of the reactor is regularly used in cooperation with staff scientists at PNNL for research projects such as the determination of short-lived fission product yields. The reactor facility features ten beam ports, including a well-characterized epithermal neutron beam port that was designed for research in boron neutron capture therapy.

Plans for the future include an anticipated application in 2011 to the U.S. NRC for a for a license modification allowing a power uprate to $1300 \mathrm{~kW}$. WSU also intends to install reactor upgrades such as a pneumatic transfer system for small samples to improve capability for analysis of short lived fission and neutron activation products and an enhanced cooling system for the reactor. Long-term strategic plans include continuing to develop a customer base for irradiation and analytical services to provide a stable funding mechanism for support of the research and education mission of the WSUNRC. 


\section{ANNUAL REPORT FOR THE RESEARCH REACTOR INFRASTRUCTURE PROGRAM}

\section{Ohio State University}

The Ohio State University Research Reactor (OSURR), in operation since 1961, is an open pool-type reactor that is utilized for a variety of instructional, research, and service activities. It is licensed for steady state operation (no pulsing) up to up to a maximum of $500 \mathrm{~kW}$ thermal power. At full power, it has a maximum thermal flux in the center of the core of $1.5 \times 10^{13} \mathrm{n} / \mathrm{cm}^{2} / \mathrm{s}$ and a total flux of $3 \times 10^{13} \mathrm{n} / \mathrm{cm}^{2} / \mathrm{s}$. The reactor is fueled with MTR-type LEU fuel and is immersed in a pool of light water that provides moderation and cooling by natural convective flow. From 1961 until 1988 it operated with HEU fuel, and in

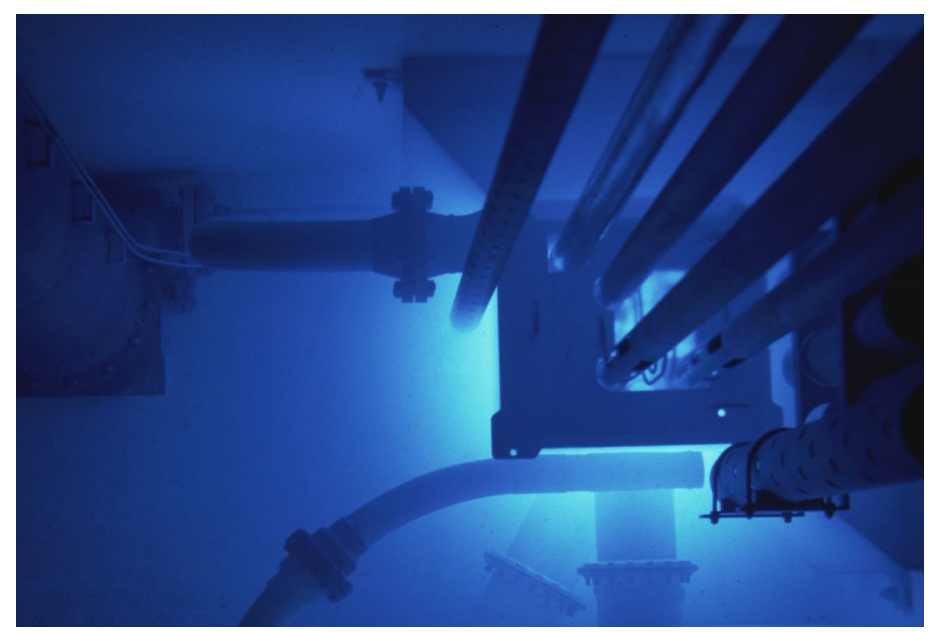
1988 it was one of the first few research reactors to convert to LEU and the first to convert to uraniumsilicide fuel. Analysis for a power uprate was part of the conversion process, and in 1990 the OSURR was granted a power increase to $500 \mathrm{~kW}$.

A number of experimental facilities converge at the reactor core, allowing simultaneous performance of multiple experiments. These facilities include two beam ports, a pneumatic transfer system, a graphite thermal column, a central irradiation facility that extends into a water-filled flux trap, two auxiliary in-core dry tube irradiation facilities, and multiple movable dry tubes that can be positioned next to the core.

The OSURR is used for a wide range of research endeavors, including neutron activation analysis (NAA), radiation-damage evaluation for electronic components and for other materials, evaluation of neutron and radiation sensitive detectors, isotope production, and biomedical experiments. The OSURR provides a variety of instructional services, including facility tours, student laboratory sessions, and research projects structured to student and faculty interests. It is not constrained by a fixed duty-cycle, allowing great flexibility in scheduling research and education and performing demonstrations and laboratories that include power changes. Many student laboratories include start-ups and shut-downs, allowing students to observe the reactor dynamics associated with these. NAA research utilizes a professional gamma-ray spectroscopy system consisting of three shielded high purity germanium spectrometers and a computer-based data collection and analysis system.

Some exciting developments are on the horizon for the OSURR. An external neutron beam facility is being designed and constructed at Beam Port \#2, which will provide a small-sized clean neutron beam for real-time testing of neutron detectors and in-situ characterization of nuclear materials with nuclear analytical technologies (e.g. neutron imaging and neutron depth profiling). In addition, a low-activation high-temperature irradiation facility for optical fiber testing is being developed as a part of a Department of Energy (DOE) NEUP research project, and a cryogenic irradiation facility will soon be created using funding from a DOE NEUP Minor Reactor Upgrade grant. The same Minor Reactor Upgrade grant is also funding installation of an upgrade to the cooling system that will enable full-power operation for prolonged irradiations during the hottest summer days, which is a capability that could not be guaranteed prior to the upgrade. 


\section{ANNUAL REPORT FOR THE RESEARCH REACTOR INFRASTRUCTURE PROGRAM}

Page: B28 of B41

\section{Kansas State University}

The Kansas State University TRIGA Mk-II reactor is a pulsing research reactor operated by the KSU Department of Mechanical and Nuclear Engineering in Manhattan, Kansas. It was constructed beginning in 1958, with initial criticality achieved in 1962, and has served a vital role in the United States' first accredited nuclear engineering program. The KSU TRIGA is presently licensed to operate at up to 1.25 MW thermal power, although power is currently limited to $550 \mathrm{~kW}$ by thermal feedback. The core was originally designed to use $19.5 \%$-enriched, $8 \%$ uranium by weight, aluminum clad fuel. The current core uses $8.5 \%$ weight percent uranium stainless-steed fuel, with plans to incorporate $12 \%$ loaded fuel in the near future to allow operation at higher power.

The experimental facilities at the reactor include: irradiation volumes such as the central thimble and reflector well; four beam ports, with different energy spectra and fluxes; a pyrolytic graphite monochromator; and a counting laboratory featuring high-purity germanium gamma spectroscopy detectors.

The reactor has four primary roles: research support; education; training; and outreach. The research support mission is partly fulfilled through

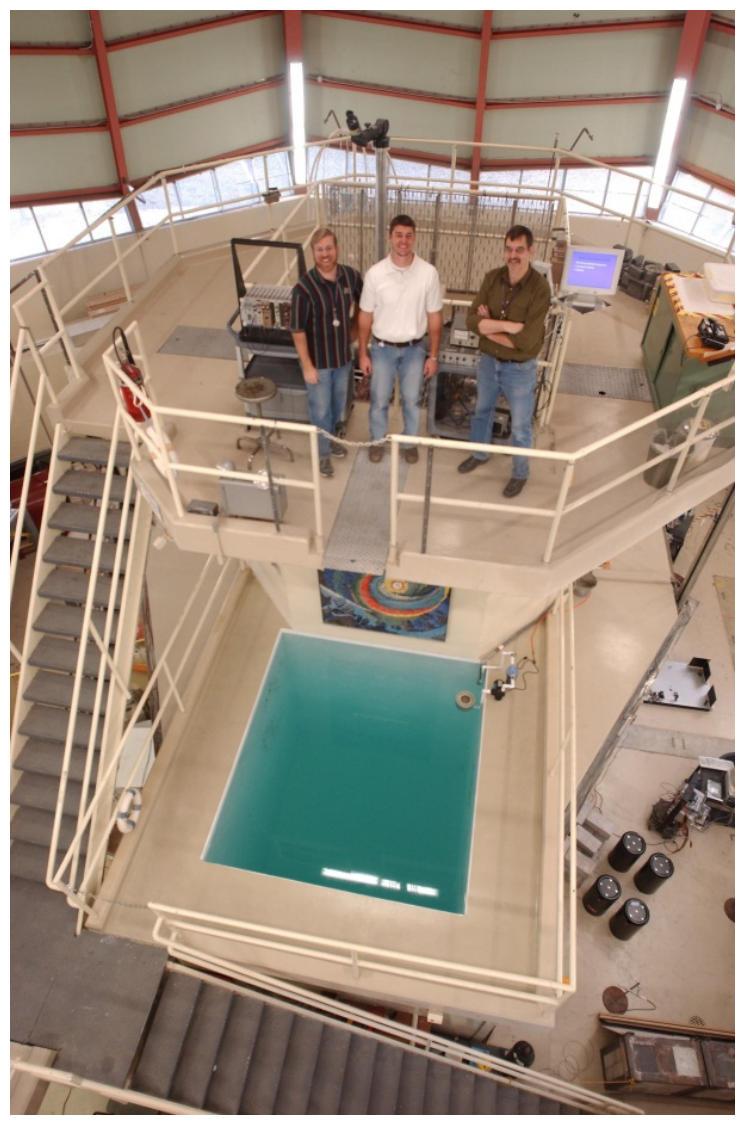
providing neutron beams for prototype neutron detector testing. This an especially vital role, as SMART Lab, a premier semiconductor neutron detector development center, is located at KSU and frequently makes use of the reactor for device testing. Another significant area of research support is neutron activation analysis, for such customers as the Indoor Environmental Research (IER) lab, entomologists, and geologists.

The reactor hosts two nuclear reactor operations laboratory courses, and provides tours and sample irradiations for numerous other courses throughout the University.

The KSU TRIGA is staffed entirely by undergraduate students, with the exception of the Reactor Manager. Therefore an important mission of the reactor is to continuously train new operators to staff the reactor as experienced personnel graduate. This gives many KSU students the opportunity to graduate as NRC-licensed Reactor Operators and Senior Reactor Operators.

Numerous tour groups visit the KSU reactor, including hundreds of visitors in a single event, Engineering Open House. Other visitors and outreach groups include the Boy Scouts, Girl Scouts, local high schools and grade schools, classes from nearby universities, and outreach programs hosted by the University.

Planned improvements at the reactor include upgraded research infrastructure, including a new neutron radiography system, and a power increase pending approval to incorporate higher-load fuel into the core. 


\section{ANNUAL REPORT FOR THE RESEARCH REACTOR INFRASTRUCTURE PROGRAM}

The Reed Research Reactor is a $250 \mathrm{~kW}$

\section{Reed College}

TRIGA ${ }^{\circledR}$ Mark I water-cooled reactor. It uses standard $8.5 \mathrm{w} / \mathrm{o}, 20 \%$ enriched TRIGA ${ }^{\circledR}$ fuel in a circular grid array. Most reactor components are clad with aluminum. The reactor sits at the bottom of a 10-foot by 15 -foot tank, 25-feet deep. The Reed Research Reactor has been used for research and educational projects in the Portland area since its establishment in 1968. A power upgrade to $500 \mathrm{~kW}$ is planned for 2011.

The Reed Reactor Facility is primarily used for instruction, research, and analysis for Reed College faculty and students. The reactor and associated facilities are used in chemistry, biology, and physics courses, as well as the senior thesis required of all Reed students. In addition to providing student research opportunities, the reactor works to

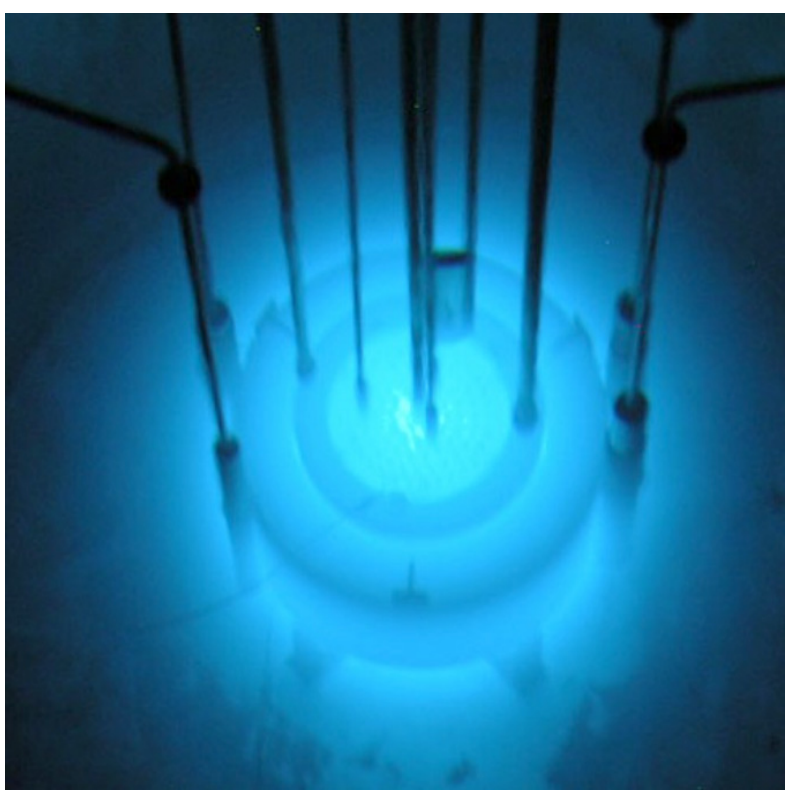
educate the surrounding community on the principles of nuclear energy and fission-reactor operation.

Between 40 and 80 students attend the reactor seminar that meets twice a week through the school year. This is out of a freshman class that averages 300. A maximum of 15 students are allowed to apply for NRC licenses each year, and the competition is tough. The students are primarily physics, chemistry, biology, and mathematics majors, but students with majors in studio arts, art history, literature, philosophy, economics, sociology, political science, classics, and religion have recently obtained licenses. The number of students who use the reactor for thesis research varies from a just a few to over a dozen each year. Each year a few students from other colleges and universities use the reactor for their research.

The full time staff consists of the reactor director and assistant director. The reactor is operated almost entirely by licensed undergraduate students working as part-time employees. There are approximately 25 student reactor operators and 15 student senior reactor operators, evenly divided between women and men. Reed is the only liberal arts college in the world with a nuclear reactor.

Irradiation Facilities include a pneumatic transfer system (rabbit), a rotating specimen rack (lazy susan) with 40 locations each of which can hold 2 samples, a central thimble (one sample), a vertical beam facility, an irradiation chamber in dummy fuel element, and foil-insertion holes. Near core, in-pool irradiation facilities can be arranged for larger samples. 


\section{ANNUAL REPORT FOR THE RESEARCH REACTOR INFRASTRUCTURE PROGRAM}

\section{University of California at Irvine}

The UCI Nuclear Reactor is operated by the Department of Chemistry for use in radiochemistry applications. The reactor is a 250 kilowatt steady-state power Mark I TRIGA reactor built by General Atomics. Pulsing is possible to about 1000 megawatts if needed. TRIGA reactors are water and zirconium hydride moderated to be especially safe for training and research purposes. The reactor first became critical in November 1969 and has been in continuous use in teaching and research since then. The facility specializes in neutron activation analysis (NAA) using thermal and epithermal neutrons. Past work has included measurements on the JFK assassination bullet lead, mercury levels in

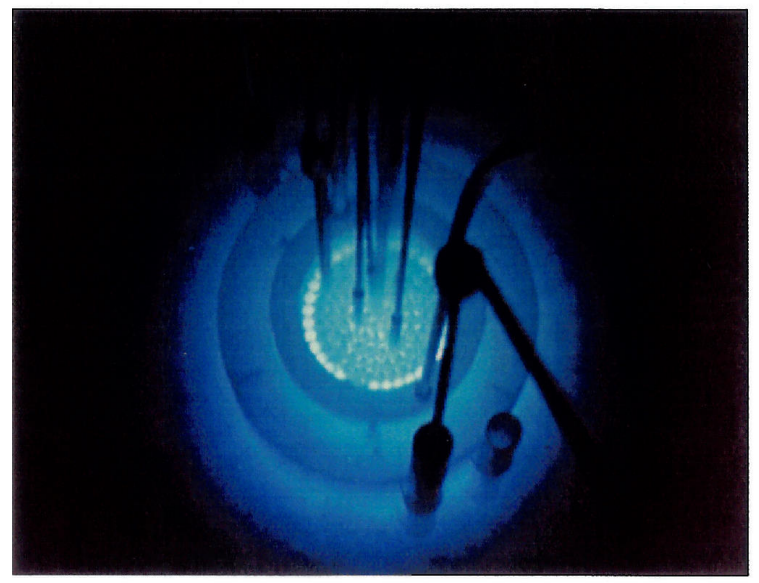
ancient specimens of swordfish and tuna, sculptures in the Getty Museum in Los Angeles, ancient bone, samples of mosaics from St Vitus Cathedral in Prague, and tracing manganese pollutants. Work is also being done to test systems and detectors for homeland security screening applications. The facility has provided short-lived radioactive isotopes on multiple occasions for tracer/tracking studies in industry and medical research.

Current research in the Department of Chemistry continues with improvement of methods for neutron activation analysis and provision of tracer radionuclides. Support for research at other universities is aiding studies in art and archeology and geo- and astro-chemistry A new program in the department of Chemical Engineering and Material Science focuses on improving solvent extraction separations of actinides and lanthanides in association with spent fuel reprocessing and uses both tracers and neutron activation analysis in that work. This program is also using the reactor, along with other techniques, to study the radiolytic chemistry of materials used in those extractions. The combination of controlled radiolysis using the TRIGA reactor, and NMR analysis of the product distribution using modern 2D NMR techniques, has improved the understanding of these liquid extraction systems. A primary function of the reactor is to support the educational programs at UCI. Courses in Radioisotope Techniques, Nuclear and Radiochemistry, and Nuclear Reactor Fundamentals are offered in the chemistry department's elective curriculum. Facilities for research as well as for tours and demonstrations are available to the many surrounding colleges and universities in the entire Southern California region. In addition a Nuclear Science Outreach early education program takes radioactivity equipment and measurements to high school classrooms and encourages visits to the facility to encourage students to learn about and consider careers in nuclear science. The reactor is also used for training reactor operators.

\section{Reactor Facilities}

The maximum steady thermal neutron flux is about $5 \times 10^{12}$ neutrons $/ \mathrm{sec} . \mathrm{cm}^{2}$. Large numbers of samples can be simultaneously irradiated at a flux of about $1 \times 10^{12}$. In-core pneumatic transfer systems are installed to return samples in 2 seconds, or $1 / 2$ second respectively. For the fast system a thermal or epithermal flux ( $\mathrm{Cd}$ lined) terminus is available in core. Samples can be returned to either a manual unload port or to automated systems including a gamma ray spectrometer station or a neutron counting station (for delayed neutron counting). Pulses can be made to provide the equivalent of a one hundred second irradiation, but with the flux peaking near $10^{16} \mathrm{n} / \mathrm{sec} . \mathrm{cm}^{2}$. 
Two gamma-ray spectrometer systems are available, each with an HPGe detector, digital MCA's and modern software systems. One is a $30 \%$ detector, one a $60 \%$ detector. A Compton suppression set-up enables measurement of low energy gamma rays and an automatic sample changer. The larger detector can be used with a 300 sample automatic sample changer for long sequenced counting.. Sodium iodide gamma detectors, proportional beta counters, helium-3 neutron counters, and a liquid scintillation system are also available. Chemistry laboratories are available within the facility and elsewhere for radiochemistry applications. Also available is a gamma irradiator with a large chamber for gamma radiation exposure studies.

\section{Future Goals}

Future goals include upgrade of instrumentation to provide education and operator training in modern digital control systems, raising the power level to enable a greater variety of experiments, and introduction of new educational experiences for students such as courses in nuclear instrumentation, nuclear regulation issues, advanced radiochemistry and combining these and existing courses into a nuclear science minor and a nuclear science concentration. Reactor operator training will be offered more widely to undergraduates as well as graduate students, and to students from other colleges and universities. In addition we are actively seeking industry collaboration in support of workforce development for the Southern California region, which includes nuclear utility operations as well as several companies with products and services in nuclear instrumentation and other nuclear science fields. 


\section{University of Maryland}

The University of Maryland Training Reactor is located in College Park, Maryland. This

TRIGA reactor is licensed to operate at $250 \mathrm{~kW}$. The reactor initially went critical on June 13, 1974 and initiated operation at full power in May 1976. This reactor is operated as needed (daily if needed) to support the educational and experimental programs of the university.

No additional information was provided by the University of Maryland for inclusion in the Program Plan document. 


\section{University of Missouri S\&T}

The University of Missouri Research Reactor (UMRR) was the first operating nuclear reactor in the state of Missouri. The initial licensed power was $10 \mathrm{~kW}$. The licensed power was upgraded to $200 \mathrm{~kW}$ in 1966. During the summer of 1992, the reactor fuel was converted from highenriched uranium fuel to low-enriched uranium. The facility is equipped with several experimental facilities and a counting laboratory that has gamma and alpha spectroscopy capabilities. The gamma spectroscopy system includes germanium and sodium-iodide detectors, associated electronics, and state-of-the art data acquisitions and spectrum analysis software. The alpha spectroscopy system consists of a surface barrier detector and data acquisition equipment. The beam-port experimental area is equipped with NE-213 and time-of flight neutron spectroscopy systems.

An average of more than 900 students from 40 different institutions participate in the Reactor Sharing Program at UMR. Ours is a model program that directly meets DOE objectives of strengthening nuclear science and engineering instruction, as well as providing research opportunities for faculty and students from non-reactor owning universities. Typical Reactor Sharing session topics

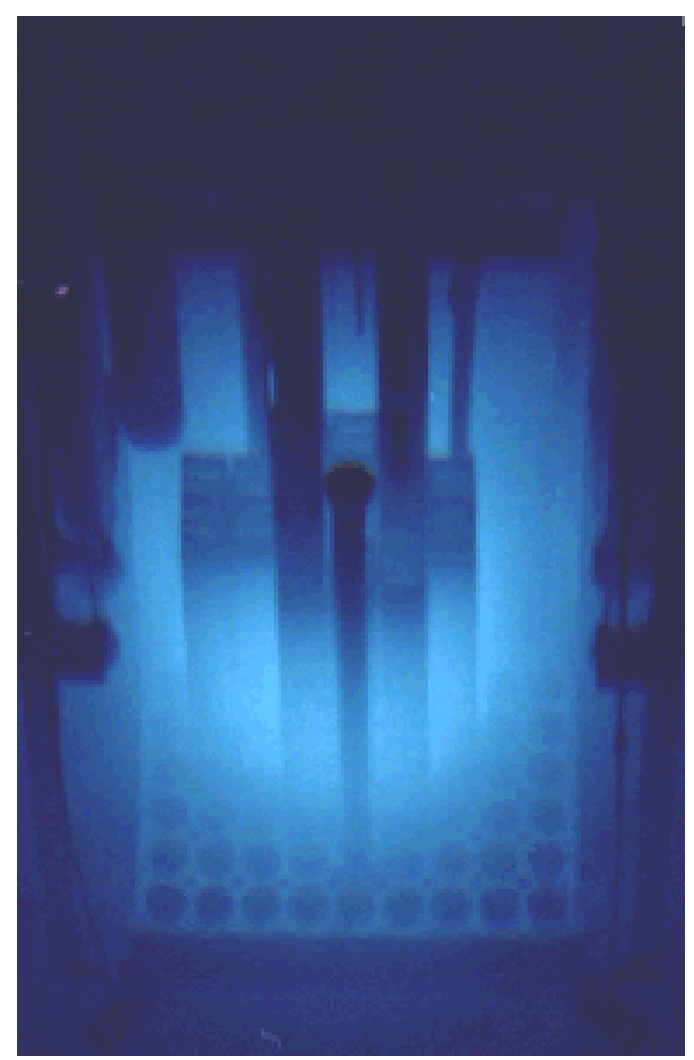
include: Radioisotope decay and Half-Life Determination, Neutron Activation Analysis, Reactor Systems and Operations, Radiation Shielding and Reactor Experiments. The UMRR also provide oneon-one individual science project research. Several high school students perform individual science fair projects every year at the UMRR facility.

Nuclear Engineering students have performed graduate level research on genetic algorithm unfolding, thermal power calibration, neutron spectroscopy and safety analyses of the UMR Reactor within the last two years. Nuclear Engineering (NE) utilize the facility for full time courses in the undergraduate program. Other departments using the UMRR include Physics, Chemistry, Chemical Engineering, Mechanical Engineering, Life Science, Civil Engineering, Basic Engineering and Engineering Management. The University of Missouri-Columbia has training for reactor theory and reactor operations with a graduate class at the UMR Reactor Facility annually. This training is a condensed version of one of the UMR NE classes. The UMRR Facility provides training for power plant reactor operators from within the state of Missouri. 


\section{University of Arizona}

After more than 51 years of safe nuclear operation, the University of Arizona Research Reactor shut down for the final time at 11:45 a.m. Tuesday, May 18, 2010.

The Arizona Research Reactor trained nuclear engineers until the University's nuclear engineering program disbanded in 1996. For the last decade, the reactor performed neutron experiments for research facilities on campus and throughout the nation. The Nuclear Reactor Laboratory operated the TRIGA MARK 1 nuclear reactor and two gamma-irradiation facilities Prior to shutdown, the users of the reactor and the gamma-irradiation facilities came from the Lunar and Planetary Laboratory, Arizona Research Laboratories Divisions, Atmospheric Sciences, Electrical and Computer Engineering, Chemical and Environmental Engineering, Aerospace and Mechanical Engineering, and General Dynamics Corporation, Scottsdale, AZ. Uses of the reactor and the gamma-irradiation facilities include neutron activation analysis of meteoritic and other geological samples, radiation induced chemical processing, testing of radiation effects in electronics, and radiation dosimetry research for homeland security and other applications.

The University of Arizona installed the reactor during 1957 and 1958. After fueling, the reactor became operational in December 1958. In 1972 and 1973, the reactor facility received reactor control upgrades and stainless steel clad fuel. In late 2010, the reactor fuel will be removed and the dismantling of the facility will commence. 


\section{ANNUAL REPORT FOR THE RESEARCH REACTOR INFRASTRUCTURE PROGRAM}

Page: B35 of B41

\section{University of Florida}

The University of Florida Training Reactor (UFTR), first licensed in 1959, was one of the first nuclear reactors on a university campus. The reactor operates at a maximum thermal power level of 100 kilowatts in a loop-type design versus the more familiar pool-type non-power reactor.

The UFTR is used within the Nuclear and Radiological Engineering Department at the University of Florida to train students to operate reactors, for laboratory courses for a variety of departments including Physics, Chemistry, Geology, Mechanical Engineering, Anthropology, and Environmental Engineering Sciences, among others, and as a radiation source for various research programs and experiments such as trace element analysis of ocean sediments, river sediments, foods, plants and many other materials. Recent trace element analysis projects utilizing neutron activation analysis include measurements of mercury and arsenic levels in fresh fish, silver in zeolites and contact lens as well as copper, chromium and arsenic in treated wood and wood ash. The facility also has a neutron radiography capability using film cassette technology. The facilities are also available to other schools at no cost for non-externally funded programs through the Department of Energy Reactor Sharing Program (DOERSP). Under DOERSP, the UFTR has been used to train technologists in medical physics and radiation protection and conduct numerous educational and research activities. External users over the past seven years include more than forty schools located around Florida and the Southeast including Florida State University, Stetson University, Florida Institute of Technology, University of South Florida (Tampa), University of Central Florida, Savannah State University, St. Petersburg and six other community colleges, as well as Crystal River High School, St. Augustine High School, and many other high schools, professional and civic groups. Indeed, we have had more than a dozen regional science fair winners perform research at our analytical laboratory in the last six years, some on projects suggested by teachers, others suggested at the UFTR.

More recently the mission vision for the UFTR has expanded to make it a more accessible and useful tool for industry, including nuclear utilities. The facility is undergoing a complete mechanical renovation and upgrade to a fully digital control system. Because the UFTR is a relatively low power reactor $(100 \mathrm{~kW})$ the irradiation capabilities, and in-core flux limits the scope of applications of which it is capable compared to many other research reactors. In view of this a research, development and modernization program was initiated to focus on the design and installation of the first fully digital control system for a nuclear reactor within the United States. The modernization procedure over the past 4 years has, or will, include a modernization of essentially the entire UFTR facility. This includes the complete replacement of the fuel with new low-enriched fuel, the fabrication and refueling processes funded by the US Department of Energy. The DOE's NNSA has also initiated the installation of a updated security system. Subsequently in 2009-10 the rector was disassembled to replace all of the major mechanical components of the facility, including water piping, fuel boxes, clutch couplings, etc. These upgrades were funded through a combination of federal, state, and industry financial support which also contribute to the upgrade of the original control system, to a fully digital control system that interfaces with a digital safety system. The digital control upgrade will incorporate a new control room, is scheduled to be completed in October 2011 and will serve as a demonstration and training resource for the integration of state-of-the-art digital control system integration with nuclear reactors. 


\section{ANNUAL REPORT FOR THE RESEARCH REACTOR INFRASTRUCTURE PROGRAM}

\section{University of Utah}

Brief History. The University of Utah TRIGA Reactor (UUTR) is licensed at $100 \mathrm{~kW}$ thermal power; reactor is an open pool-type. Currently, the UUTR operates at the maximum power of $90 \mathrm{~kW}$. The UUTR uses TRIGA standard 8.5 w/o, 20\% enriched fuel and heavy water and graphite elements as reflectors. The reactor construction started in 1972; the UUTR went critical in October 1975.

Mission and Vision. The UUTR reactor is used for research, training of our students to operate the reactor, and education with hands-on experience for 35 years within the University of Utah. Main mission of the UUTR is that it represents an integral part of our nuclear engineering program, provides broad opportunities for

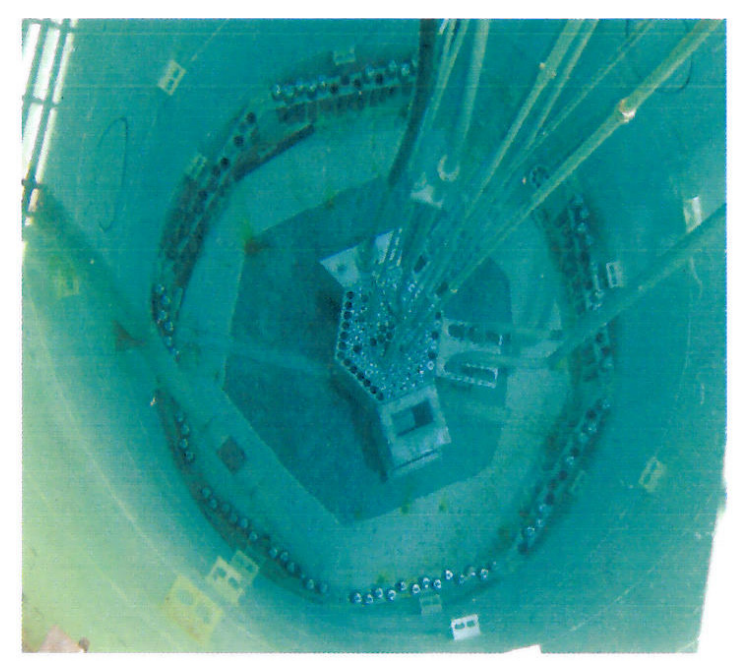
academic research and services to industry, is used to train students for operating licenses and is used for educational outreach. Our vision is to establish the UUTR as a hub for hands-on learning of nuclear engineering principles in western states.

Capabilities and Use of UUTR. In 2009 we have established a new nuclear engineering curriculum inclusive of advanced graduate courses and a minor degree in nuclear engineering, centering on the hands-on experience using the UUTR in majority of our courses, as well as using UUTR in enhancing course work in radiochemistry, nuclear forensics, nuclear safeguards simulation \& visualizations of reactor neutronics and other reactor phenomena. Recently we also provide courses remotely and accept students from other Universities for laboratory practices at the UUTR facility. The UUTR and the "Utah Energy Playground" Museum provide significant educational outreach to the local community through the traditional tours and demonstrations. Approximately 500 visitors mainly from elementary, junior high and high schools visit the UUTR and Museum every year. Besides serving the academic community of the University of Utah and local community, the UUTR serves also commercial and government entities, other Universities and National Laboratories in providing a variety of nuclear engineering services and educational and research opportunities. Research is supported through various grants and awards, as well as recently re-established services by the neutron activation analysis (NAA); our main service-based research is in a field of neutron hardness tests provided for the U.S. Air Force. Irradiation facilities at the UUTR include Fast Neutron Irradiation facility (FNIF), Thermal Neutron Irradiator (TI), Pneumatic Irradiator (PI), and Central Irradiator (CI). The maximum total neutron flux at $90 \mathrm{~kW}$ is $3.6 \times 10^{12}$ neutrons $/ \mathrm{cm}^{2}$-s in CI. The UUTR has a unique FNIF; that facility provides $1 \mathrm{MeV}$ equivalent fast neutron beam with the maximum neutron flux of $2.1 \times 10^{11}$ neutrons $/ \mathrm{cm}^{2}$-sec. The TI provides well-thermalized neutron flux of $3.69 \times 10^{11}$ neutrons $/ \mathrm{cm}^{2}$-sec. The NAA program at the UUTR is redeveloped to increase the use of our reactor. The PI (Pneumatic Irridiator) that transfers a sample to the detector using a pressurized helium gas to minimize contamination and dose to operating staff is in the re-modeling process to maximize its capability.

Planned and Desired Future at the UUTR. In years to come we plan to increase the total power output of the UUTR; develop few benchmark examples for testing new computational efforts in accurately predicting reactor core performances; establish rather unique Boron Neutron Capture Therapy experiments tailored toward new modes of targeted treatments for aggressive cancers; design and build neutron radiography using under-water removable beam ports, and improve NAA service lines. 


\section{Worcester Polytechnic Institute}

The WPI Nuclear Reactor Facility first began operations in 1959 primarily as a tool for nuclear engineering education. In 2010 the reactor facility was shut down and is currently undergoing planning for decommissioning. Prior to shutdown, the facility provided a hands on approach to teaching by encouraging student utilization of each facet of the reactor, its control systems, experimental facilities, and laboratory equipment. This type of complete access to a working nuclear reactor was unique for an undergraduate nuclear engineering program.

The open pool reactor was licensed for a maximum thermal output of $10 \mathrm{~kW}$, which allowed a maximum thermal neutron flux of about 1x10E11 nv, and was designed such that the core was readily accessible. Facility equipment included a beam port for neutron beam experiments including neutron radiography, a graphite thermal column for neutron diffusion studies, two germanium semiconductor detector systems for spectrometry studies including neutron activation analysis, and an array of sodium iodide scintillation and Geiger detector systems for various laboratory exercises. Both the control console and the peripheral laboratory equipment used for student projects and laboratory exercises are located in the reactor room.

Nuclear Engineering at WPI is an undergraduate program under the Mechanical Engineering department. Seven nuclear engineering courses and project opportunities are offered for students of all disciplines. The available courses include basic nuclear concepts, radiological safety, reactor theory, and nuclear waste disposal. Laboratory experience accompanies most of these courses in addition to a separate nuclear engineering laboratory course. Participation in elements of the program is strongly interdisciplinary. The nuclear engineering courses compliment several other programs at WPI, including; physics, chemistry, biotechnology, electrical engineering, and civil engineering. WPI also places a strong emphasis on project work, and the reactor facility has been a focal point for much project work in the nuclear area. Faculties from other departments made use of the facility, as well as several from other colleges in the area, who routinely utilized the facility under the Reactor Sharing Program.

The Reactor Sharing Program evolved such that it provided intensive, extended use to a few users, rather than quick and limited use to many users. A number of institutions have made use of the WPI Reactor under the Reactor Sharing Program. And, as has been the case for many years, tours, demonstrations, and presentations were made to several area pre-college students. The facility staff recognized the need to interest school children, and their teachers, in the nuclear sciences. A concerted effort was made to reach out to area high schools and elementary grade students. 


\section{Purdue University}

The Purdue University School of Nuclear Engineering operates the PUR-1 reactor. This reactor is the first and only operating reactor in the state of Indiana. It is used as an integral part of both the undergraduate and graduate programs in Nuclear Engineering, as well as having a highly visible role in public education about nuclear processes.

The PUR-1 reactor is a $1 \mathrm{~kW}$ pool type reactor that utilizes flat plate MTR type fuel. First critical on August $30^{\text {th }}$ in 1962, the reactor was re-licensed in 1988 for an

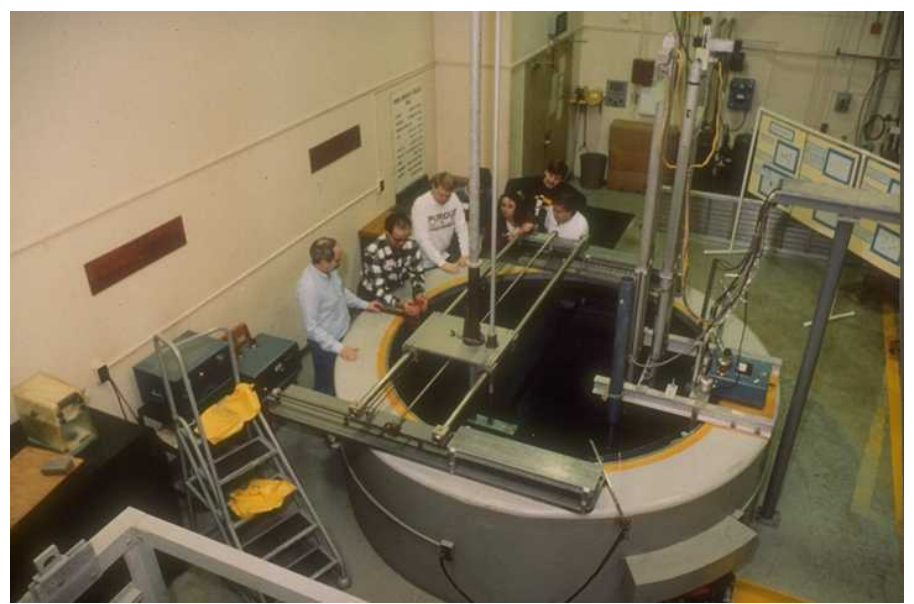
additional 20 years of operation. The reactor is operated as needed for classes, presentations, and research.

The primary mission of the reactor is education, not only of Purdue University students, but of area high school students and the general public as well. The reactor is also available for research projects by University users as well as outside groups.

There are two courses in Nuclear Engineering (one undergraduate and one graduate) that make direct use of the reactor. Specifically, the students operate the reactor and perform experiments to learn reactor physics principles. There is also a third course in the School of Health Science wherein the students calibrate some of the reactor instrumentation and irradiate samples for analysis in their lab course.

The PUR-1 reactor facility also runs a neutron activation analysis class for area high school students under a reactor sharing grant. These students spend the entire day in our lab learning how to use gamma spectrometers, in conjunction with the reactor to produce samples for them to identify. This program has operated for the last fifteen years and has an average of 6-7 high schools with 8-10 students each

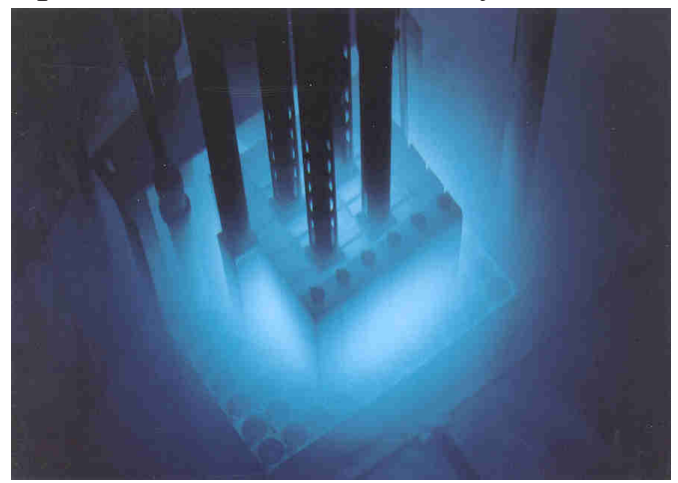
participating each year. This year, only two weeks after invitations were mailed to teachers, four groups involving fifty students have already responded.

The reactor is also assigned a prominent role in educating the public about nuclear processes. Lecture/tour combinations are offered to student groups, Purdue classes, and the community. This emphasis was increased in the last three years and an average of 800-1000 people toured the facility each of those years. We are currently collaborating with Rush University Medical Center to perform preliminary work on a variation of the Boron Neutron Capture Therapy (BNCT) method for treating malignant brain tumors. 


\section{Idaho State University}

Idaho State University has an AGN-201 Training Reactor, designed and built in the 1950s by Aerjojet General Corporation, as an ultra safe training reactor. About 30 of these were built and distributed to various universities by the Atomic energy Commission. Idaho State University receive its in 1967, and the unit is housed in the reactor room in the basement of the Lillibridge Engineering Building.

These are considered "training" reactors, not research reactors, though we have done a number of both MS theses and one $\mathrm{PhD}$ dissertation using the reactor as the base experimental device, though it is licensed for only 5 watts power.

This reactor type is very unique, probably the lowest critical mass of LEU (low enriched uranium, 19.9\% U-235) of any device that has ever been built. It has about 672 grams of U-235 (2688 grams of $\mathrm{U}-238$ ), and at $15 \mathrm{C}$ has a k-excess of about $0.5 \%$ delta $\mathrm{k}$.

This subcritical facility presents a significant contrast and challenge to the students, concerning reactor physics design and the optimum designs to achieve criticality. WE have two NRC licenses, one for the Reactor, and one for the SNM in the Subcritical Facility.

Idaho State University has no external commercial customers. ISU has a number of research contracts in cooperation with the INL, and several of these use the AGN-201 as part of the research.

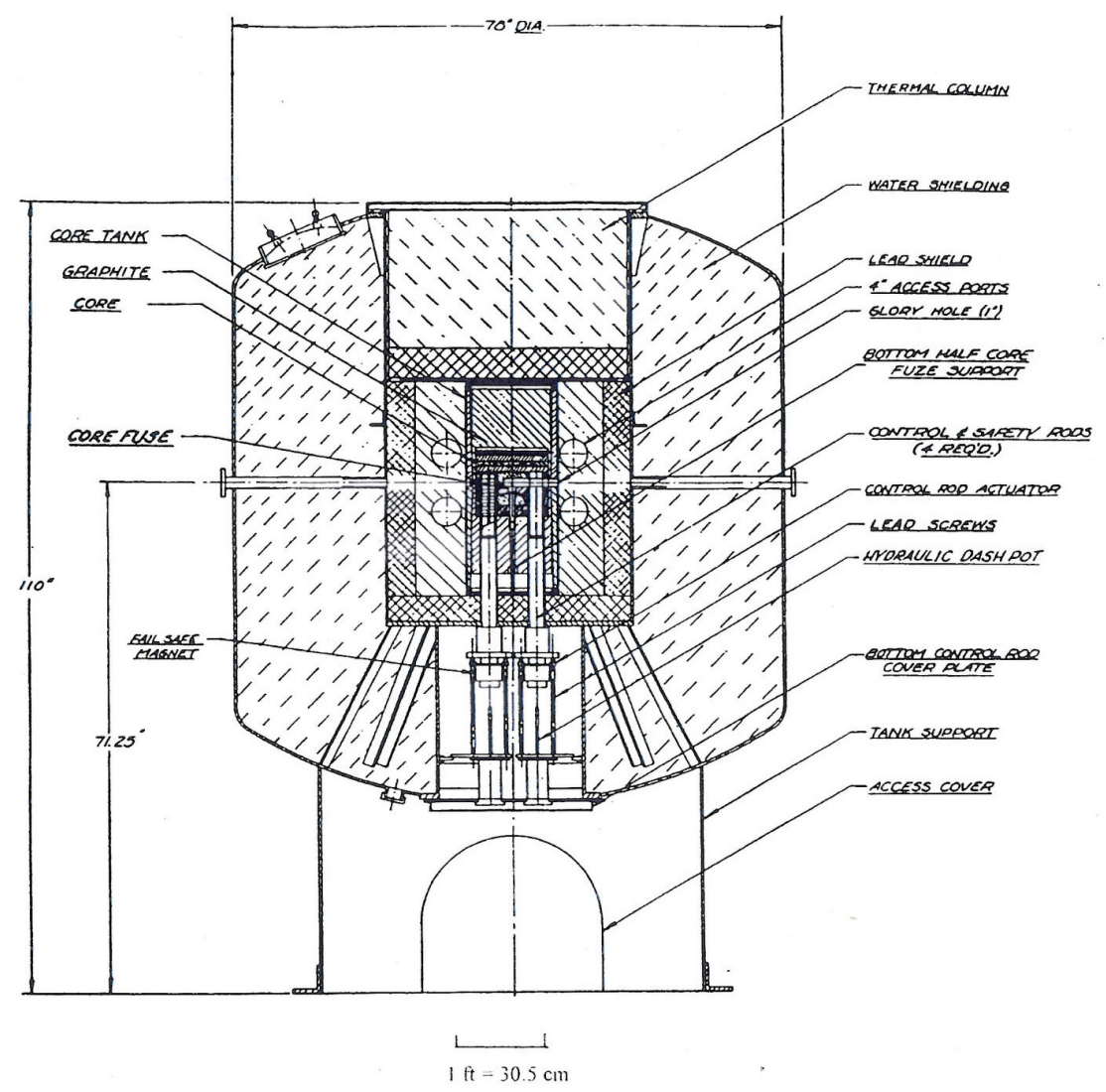

AGN-201 reactor unit. 


\section{ANNUAL REPORT FOR THE RESEARCH REACTOR INFRASTRUCTURE PROGRAM}

\section{University of New Mexico}

The University of New Mexico has operated its AGN-201M reactor at its Albuquerque campus since it arrived from the University of California at Berkeley in 1966. In 1986, the license for operation was renewed for another 20 years. expiring on March 20, 2007. License renewal has been filed with the NRC and another 20 year license is expected to be granted April 2010. Although many universities have decommissioned their reactors, UNM feels that an operating reactor is an invaluable teaching tool for our nuclear engineering program. With the license renewal application in 2007, we renewed our

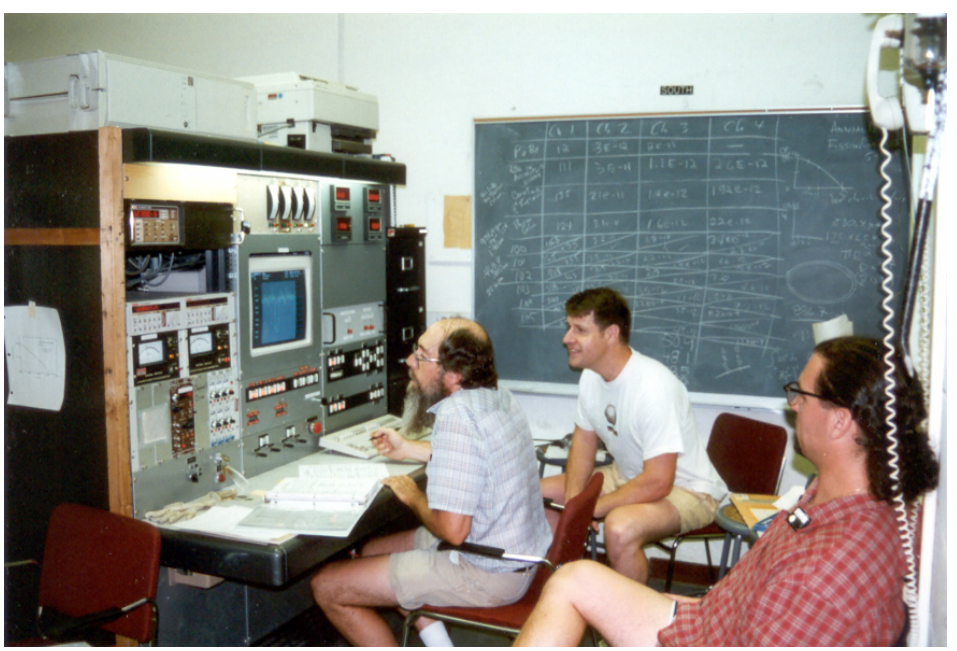
commitment to maintaining and using this facility for the next 20 years. The AGN-201M reactor continues to be used extensively for teaching and for experiments as part of our undergraduate and graduate programs. Because of the low power level, the AGN fuel can be removed and handled by students providing hands-on opportunities to learn about handling radioactive materials and performing an approach to critical experiment. Other experiments include: reactor period and reactivity measurements, importance function measurements, neutron temperature measurements, reactor power and fluence measurements, control rod calibrations, sample activation, and void coefficient measurements. We also use the reactor in support of our faculty and student research efforts. It is regularly used in the Fall and Summer Semesters to provide demonstrations and support research. Its heaviest use occurs during the Spring semester when both seniors and graduate students are enrolled in the reactor laboratory classes. During this time, the reactor is used twice a week for an average of 10 hours of operational time per week.

The AGN reactor is a homogeneous thermal reactor, used for teaching and training. The reactor core is $25.6 \mathrm{~cm}$ diameter by $24 \mathrm{~cm}$ high and it consists of nine fuel discs that are separated at the mid-plane by a thin aluminum baffle. A 1-inch inside diameter glory hole passes through the center of the core in the radial direction. The AGN-201M reactor can provide neutrons with a flux of $2.5 \times 10^{8}$ thermal neutrons $/ \mathrm{cm}^{2}-$ $\mathrm{sec}$ at the centerline in a $2.3 \mathrm{~cm}$ diameter experiment port. The reactor is licensed by the US Nuclear Regulatory Commission. Operation must be done under the supervision of licensed Reactor Supervisors (Currently there are 3 licensed Reactor Supervisors on staff).

\section{Significant Research using Reactor}

Two research projects have been carried out using the AGN-201M reactor over the past ten years. First, the reactor has been used to generate reference samples for a project which analyzes beam energy spectra from pulsed power facilities. Foils of different materials are activated in the reactor to determine their responses to thermal neutrons and to analyze content particularly with respect to impurities that may be present. The second project is a small sample reactivity measurement technique that is being applied to geologic samples to determine their thermal neutron cross sections and relative water content. This work has application in both the oil well core logging industry and in the waste disposal area where pulsed neutron logging techniques are widely used. Again the effort of the research is to create references which can be used to validate and interpret pulsed neutron data. 


\section{ANNUAL REPORT FOR THE RESEARCH REACTOR INFRASTRUCTURE PROGRAM}

Page: B41 of B41

\section{Rensselaer Polytechnic Institute}

The Rensselaer Polytechnic Institute Reactor Critical Facility (RCF) is a zero power, open pooltype reactor, fueled with SPERT F1-LEU fuel pins. The reactor first went critical in 1957 as a critical facility for the Army packaged-power reactor program utilizing high-enriched, plate fuel. RPI has operated the facility since 1963 as a research and teaching facility. It underwent a conversion from high-enriched plate fuel to low-enriched $(4.81 \mathrm{w} / \mathrm{o})$ $\mathrm{UO}_{2}$ pins in 1985-1986.

The RCF serves a vital role in the nuclear engineering curriculum at RPI. The Critical Reactor Laboratory class has been very popular and has recently been made a required class in the undergraduate nuclear engineering curriculum. In

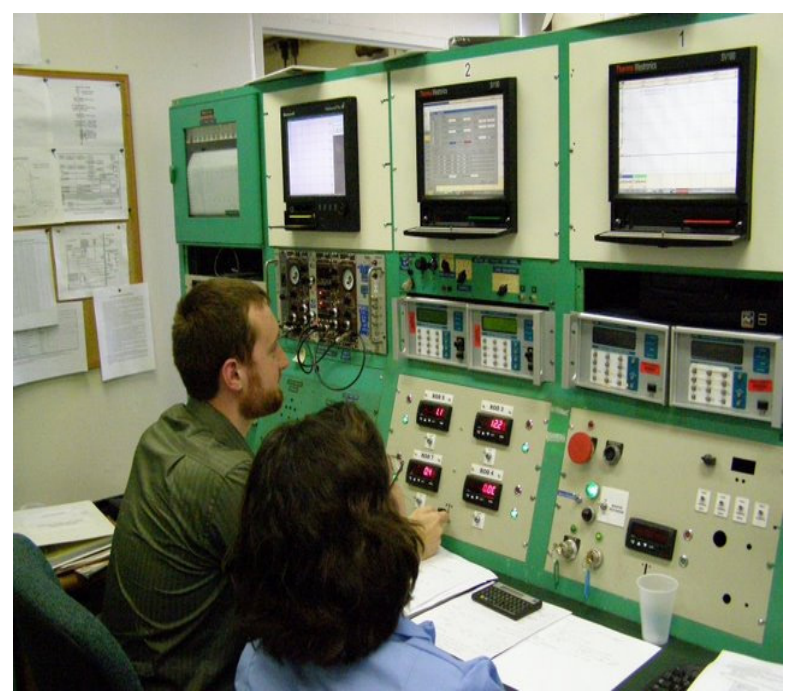
addition, many undergraduate research projects, Master's level theses and several Ph.D. theses have been performed utilizing the reactor.

The facility is also in the process of providing distance and blended learning opportunities. Several remotely controlled cameras provide the capability to tape class room lectures and experiments. RPI is working toward full videoconferencing capabilities to support remote teaching.

Since the RCF is uniquely configured to support critical benchmark experiments, most of the research activity has been in the area of critical benchmark measurements. This has included reactivity worth measurements of new poison materials and critical configurations using different metal reflector materials.

The facility possesses a gamma-spectroscopy capability using a NaI detector and MCA card in a

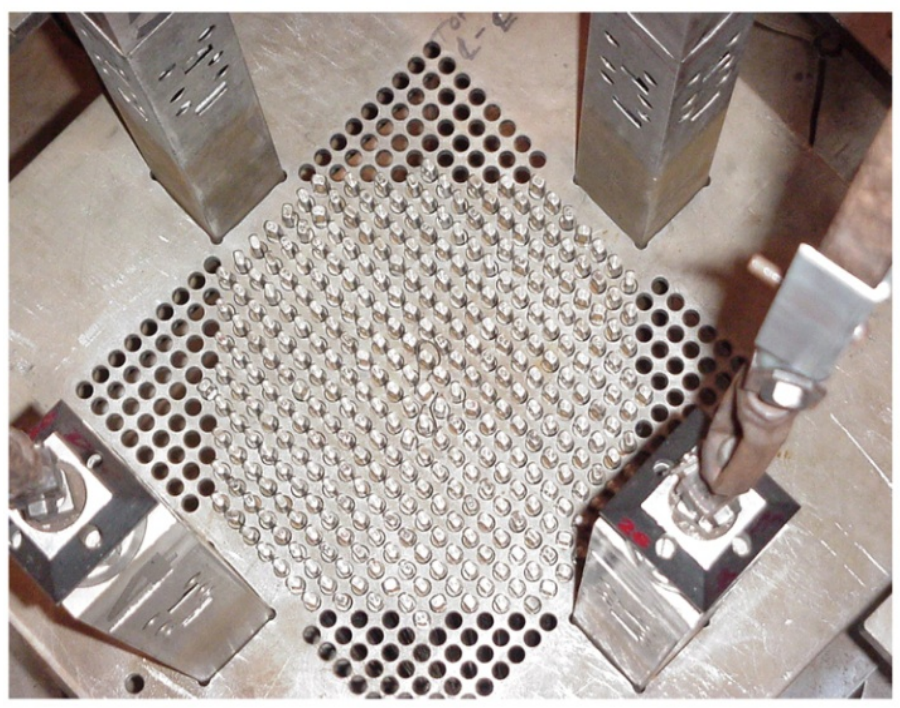
PC-based system. The spectroscopy equipment is used for foil activation experiments and gamma scanning of activated fuel pins for power mapping experiments.

Future enhancements to the facility will be directed towards improving the distance and blended learning capabilities with full videoconferencing capabilities and expanding the role of the facility in the undergraduate nuclear engineering curriculum. Efforts to characterize the facility for performing highquality critical benchmarks are also being pursued. Upgrading the gamma-ray spectroscopy experiment is also planned with a replacement of the $\mathrm{NaI}$ system with a more modern germanium detector system. 